\title{
Development of a Non-stationary Standardized Precipitation Evapotranspiration Index (NSPEI) for Drought Monitoring in a Changing Climate
}

Javad Bazrafshan ( $\sim$ jbazr@ut.ac.ir)

University of Tehran https://orcid.org/0000-0002-6721-8990

Majid Cheraghalizadeh

University of Tehran

Kokab Shahgholian

University of Tehran

\section{Research Article}

Keywords: Drought, Non-stationary, SPEI, NSPEI, GAMLSS, Iran

Posted Date: June 9th, 2021

DOI: https://doi.org/10.21203/rs.3.rs-573309/v1

License: (c) (i) This work is licensed under a Creative Commons Attribution 4.0 International License.

Read Full License 


\section{Development of a Non-stationary Standardized Precipitation Evapotranspiration Index (NSPEI) for Drought Monitoring in a Changing Climate}

2

3

\author{
Javad Bazrafshan', Majid Cheraghalizadeh ${ }^{2}$, Kokab Shahgholian $^{3}$ \\ Karaj, Iran. Email: majid_ab86@yahoo.com 9 \\ ${ }^{1}$ Corresponding Author, Associate Professor, Department of Irrigation and Reclamation \\ Engineering, University of Tehran, Karaj, Iran. Email: jbazr@ut.ac.ir $\quad 7$ \\ ${ }^{2} \mathrm{PhD}$ Student, Department of Irrigation and Reclamation Engineering, University of Tehran, 8
}

${ }^{3} \mathrm{PhD}$ Student, Department of Irrigation and Reclamation Engineering, University of Tehran, 10 Karaj, Iran. Email: nadiashahgholian@gmail.com 11

\section{Abstract}

In a changing climate, drought indices as well as drought definitions need to be revisited, because some statistical properties, such as long-term mean, of climate series may change 15 over time. The study aims to develop a Non-stationary Standardized Precipitation 16 Evapotranspiration Index (NSPEI) for reliable and robust quantification of drought 17 characteristics in a changing environment. The proposed indicator is based on a non18 stationary log-logistic probability distribution, assuming the location parameter of the 19 distribution is a multivariable function of time and climate indices, as covariates. The optimal 20 non-stationary model was obtained using a forward selection method in the framework of 21 Generalized Additive Models in Location, Scale and Shape (GAMLSS) algorithm. The Non22 stationary and Stationary forms of SPEI (i.e. NSPEI and SSPEI) were calculated using the 23 monthly precipitation and temperature data of 32 weather stations in Iran for the common 24 period of 1964-2014. The results showed that almost at all the stations studied, the non25 stationary log-logistic distributions outperformed the stationary one. Both drought indicators 26 SSPEI and NSPEI significantly differed in terms of spatial and temporal variations of drought 27 characteristics. While SSPEI identified the long-term and continuous drought/wet events, 
NSPEI revealed the short-term and frequent drought/wet periods at almost all the stations of

interest. Finally, it was revealed that NSPEI, compared to SSPEI, was a more reliable and

robust indicator of drought duration and drought termination in vegetation cover during the

severest drought period (the 2008 drought), and therefore, was suggested as a suitable

Keywords: Drought; Non-stationary; SPEI; NSPEI; GAMLSS; Iran.

\section{Introduction}

Drought, as a recurrent and normal feature of climate, affects economy, society, and

environment across the globe (Wilhite 2000). Historical evidence shows that Iran has

suffered from the long-term and devastating droughts during few centuries ago. For instance, $\quad 38$

the intensive famines during 1870-1872 and 1917-1919 which occurred due to drought

occurrences, endangered water and food security throughout the country, and destroyed half

of the population (De Planhol 2012). Bazrafshan et al. (2017) specified that during 1894-

2010, Iran (with average annual precipitation of $254 \mathrm{~mm}$ ) had experienced 23 drought events,

ranging from 1 to 10 years. The 2008-2010 and 1998-2002 droughts, with total precipitation

deficits of 176.1 and $180.4 \mathrm{~mm}$, respectively, were identified as the most severe and

Drought is conventionally defined as a temporary period of moisture deficit relative to

Van Loon 2015). This simple definition, however, cannot be used in the regional studies of

drought. To this end, drought indices are used. Using standardization of moisture 50 deficiencies, drought indices enable us to compare different locations based on their drought 51 characteristics (such as severity and duration) (Şen 2015). These indices have been used to 
The origin of all droughts starts from lack of precipitation (meteorological drought). It 54 gradually spreads to the other sectors in the form of deficiency in soil moisture (agricultural 55 drought) and reduction of surface water and groundwater resources (hydrological drought) 56 (Bhardwaj et al. 2020, Huang et al. 2017, Van Lanen 2006). Therefore, the accurate 57 monitoring of meteorological drought would be very important in predicting agricultural and 58 hydrological droughts. In this research, meteorological drought is considered.

Precipitation and evapotranspiration are the two main variables of meteorological 60 drought indices (Beguería et al. 2014, Tirivarombo et al. 2018, Vicente-Serrano et al. 2010). 61 In the energy-limited areas such as humid and rainy areas of northern Iran, precipitation alone 62 is sufficient to monitor meteorological drought. In the water-limited areas such as the hyper 63 arid and semi-arid regions of Iran, in addition to precipitation, atmospheric evaporative 64 demand (AED) also plays a crucial role and need to be taken into account for effective 65 drought monitoring and management (Bazrafshan 2017). 66

During the last two decades, the Standardized Precipitation Index (SPI), developed by 67 McKee et al. (1993), have been widely used for assessing the temporal and spatial variations 68 of meteorological droughts across the globe. The first feature of SPI is that it is 69 dimensionless, which allows the index to be comparable in different geographical locations. $\quad 70$ The other feature of SPI is its ability to be calculated on multiple timescales (short-term, 71 medium-term, and long-term) that provide a projection of the drought occurrence in soil, 72 surface water and groundwater resources (Mishra and Singh, 2011). The SPI substantially fits 73 the appropriate probability distribution (e.g. Gamma) to a series of cumulative precipitation at 74 a given timescale, and then, transforming the probability of any cumulative precipitation 75 value to the standard normal variate (called SPI) (Guenang and Kamga 2014, WMO 2012). 76 The mathematical algorithm governing this index became so popular that several drought 77 indices (both univariate and multivariate) were developed based on the same mathematical 78 
algorithm (Bateni et al. 2018, Bazrafshan et al. 2014, Vicente-Serrano et al. 2010). One of the 79 drought indices that follows the mathematical algorithm of SPI is the Standardized 80 Precipitation Evapotranspiration index (SPEI) (Vicente-Serrano et al. 2010). Instead of the 81 precipitation deficiency with respect to the long-term average, SPEI is calculated based on 82 the precipitation shortage with respect to AED at multiple timescales. Also, instead of a 83 stationary Gamma distribution, it uses a stationary three-parameter log-logistic distribution 84 (Beguería et al. 2014, Hernandez and Uddameri 2014, Vicente-Serrano et al. 2010). SPEI has 85 all the benefits of SPI. A feature that makes SPEI superior to SPI is that it can incorporate the 86 effect of global warming into the severity of drought. This effect appeared in the initial 87 version of SPEI, in which monthly mean temperature was used to calculate AED from the 88 Thornthwaite method (Thornthwaite 1948). The issue of selecting the appropriate method for 89 calculating AED can be crucial in the SPEI computation, because the method of calculating 90 AED may significantly affect the SPEI results. For example, Zarei and Mahmoudi (2020) 91 examined the effect of different methods of calculating AED on the SPEI calculations at a 92 number of meteorological stations in Iran. Using some statistical tests and metrics, they 93 indicated that there were no significant differences between the SPEIs calculated by the 94 method Thornthwaite (1948) and those calculated by the FAO Penman-Monteith reference 95 method (Allen et al. 1998). Mavromatis (2007) also showed that the use of simple and 96 complex methods to calculate AED in a drought index such as Palmer Drought Severity 97 Drought Index (PDSI) produced similar results.

Climate change, in the most optimistic case, will change the average of climatic 99 elements such as precipitation and air temperature (IPCC 2014), and this change in the 100 average would not be consistent with the existing definitions of droughts. Therefore, 101 definition of drought in a changing climate needs to be revisited. The main effects of future climate change are the regional increase/decrease of precipitation and the global increase in 
air temperature (IPCC 2014). Under stationary climatic conditions and assuming low

variability of other climatic factors such as air temperature, the traditional SPI is capable of representing the effect of precipitation variations on drought (Russo et al. 2013). Under nonstationarity of precipitation data, the development of a Non-stationary SPI (NSPI) for drought assessment has been proposed (Li et al. 2015, Rashid and Beecham 2019, Wang et al. 2015). Although the NSPI considers the precipitation changes in a changing climate, it, like the SPI, 109 is unable to demonstrate the effect of global warming on drought characteristics (Asadi Zarch et al. 2015). In such condition, as stated earlier, the SPEI may be a suitable option. However, SPEI calculations are also reliable under assumption of climate stationarity.

Incorporating the environmental changes in the context of drought indices is an important issue which is not regarded in the traditional drought indices ( $\mathrm{Li}$ et al. 2015). So far, efforts have been made to develop drought indices under climate non-stationarity. According to literature, the first study in this context was carried out by Russo et al. (2013). They believed that the effect of climate change signals on climate variables for the periods longer than 30 years is significant, and therefore, the results of drought indices such as SPI would not be reliable due to the changes in the statistical parameters (especially, location parameter) of Gamma distribution for those long periods. To overcome this issue, they 120 developed a non-stationary Gamma distribution in the SPI structure and called the new index as the Standardized non-stationary Precipitation Index (SnsPI). Wang et al. (2015) proposed a time-dependent Standardized Precipitation Index (SPIt) in the Luanhe River Basin, China. Non-stationarity in SPIt was modeled by fitting a Gamma distribution with a time-dependent location parameter to the summer precipitation data. Non-stationary models were introduced 125 as polynomial regression functions with the degrees less than or equal to 3 of time within the Generalized Additive Models in Location, Scale and Shape (GAMLSS) framework. The optimal non-stationary model was selected by minimizing the Akaike Information Criterion 
showed that in most situations, the non-stationary Gamma distribution has a better fit to the monitoring in a changing climate in Iran. They considered the location parameter of the lognormal probability distribution as a polynomial regression function of time. Both stationary and non-stationary forms of log-normal distribution were fitted to the series of the stations, the non-stationary log-normal distribution was able to simulate the monotonic downward trend identified by the Mann-Kendall test, and outperformed the stationary one.

One of the important limitations of time-dependent drought indices such as SnsPI, SPIt, may be part of a larger cycle which are not manifest in current data ( $\mathrm{Li}$ et al. 2015). Furthermore, the time-dependent non-stationary models cannot accurately represent the variability in distribution parameters (Serinaldi and Kilsby 2015). To resolve this issue, the number of large-scale climate indices, as covariates, to estimate the location parameter of Gamma distribution on the basis of three groups of models (i.e. stationary, time-dependent 
drought assessment in the same basin. Also, due to the fact that the non-stationary models use the lagged values of climate indices, the variability of the distribution parameters over time is maintained in the NSPI calculations. Additionally, the NSPI was able to simulate well the historical droughts of the basin as well as their spatiotemporal characteristics. Wang et al. (2020) presented a Non-stationary Standardized Streamflow Index (NSSI) in the Luanhe River Basin of China. The NSSI considers the non-stationarities caused by both the climatic and anthropogenic effects on the river flow. The climatic effects were incorporated into the framework of non-stationary models using the climate indices (i.e. teleconnections) and the anthropogenic effects using the Soil and Water Assessment Tools (SWAT) model. Results showed that NSSI describes the temporal and spatial variability of the river flow better than the Standardized Streamflow Index (SSI). Kang and Jiang (2019) offered a standardized streamflow index for monitoring hydrological drought under the environmental change 165 conditions of China's Yangtze River. The statistical tests did not confirm the stationary 166 assumption of the streamflow data. Therefore, the two covariates, time and modified 167 reservoir index, were applied to model the non-stationarity in the streamflow data. They 168 concluded that the modified reservoir index incorporated in the non-stationary model reported more severe droughts than the stationary one. However, the time-dependent non170 stationary model underestimated the risk of drought events. Rashid and Beecham (2019) developed a Non-stationary Standardized Precipitation Index (NSPI) within the GAMLSS algorithm for drought monitoring in South Australia. They used climate signals as covariates to model the non-stationarity in precipitation data. The results showed the superiority of the non-stationary models to the stationary model in representing drought characteristics. They concluded that the recurrence period of the drought events of larger than any amount of drought severity and duration estimated by NSPI was significantly different from those of the Stationary Standardized Precipitation Index (SSPI). 
As mentioned earlier, in a changing environment where either both precipitation and

AED variables or one of them are non-stationary, the drought assessment and the statistical

continuation and progression of the previous studies, there will be a need to develop the non-

stationary form of SPEI for more robust and reliable monitoring of meteorological drought in

a changing climate. The purpose of this study is to propose a Non-stationary Standardized

Evapotranspiration Precipitation Index (NSPEI) under changing climate conditions in Iran.

Non-stationary modeling of climate variables is carried out using the covariates, namely, time

and the teleconnections, such as ENSO and NAO, affecting the climate of Iran. Both

stationary and non-stationary indices are compared in terms of several temporal and spatial drought characteristics. Finally, the temporal variations of vegetation cover and both stationary and non-stationary drought indices were evaluated during the severest drought period (the 2008 drought) in Iran, in order to introduce a suitable drought index to monitor drought impact on vegetation cover.

\section{Materials and Methods}

\subsection{Study Area: Geographical Characteristics, Climate, and Teleconnections}

Geographically, Iran is located in West Asia in the range of $63^{\circ}-44^{\circ}$ East longitude and $29^{\circ}-$

$35^{\circ}$ North latitude. Most of Iran's climate is arid (64\%) and semi-arid (20\%), due to its

location in the subtropical high-pressure subsidence zone. In addition, about $16 \%$ of its area

is Mediterranean to very humid (Khalili 1997). The main controllers of Iran's climate are:

latitude, altitude, and distance from the seas and oceans. The latitudinal expanse of Iran, in 
influenced by the near (Caspian Sea, the Persian Gulf and Oman Sea) and distant (Black Sea,

Mediterranean Sea, Indian Ocean, Atlantic Ocean, and the Red Sea) water bodies (Khalili and

Rahimi 2018). The main sources of precipitation in Iran are the low pressures (mainly

Mediterranean) that influence the spatial and temporal distribution of precipitation directly during seven months of the year from mid-October to mid-March (Khalili and Rahimi 2014).

Siberian's high pressure also plays an important role in the precipitation occurrence on the

southern shores of the Caspian Sea in November and December. Precipitation amount

decreases from the west to the east and from the north to the south of the country. The long-

term average annual precipitation in Iran is $254 \mathrm{~mm}$, which varies between $13 \mathrm{~mm}$ and 2003

$\mathrm{mm}$ across the country. The long-term average temperature in the country varies between

$1.6^{\circ} \mathrm{C}$ (at the elevation of $3000 \mathrm{~m}$ ) to $28^{\circ} \mathrm{C}$ (on the southern coast) (Khalili 1997, Khalili and

Rahimi 2018). Generally, climate change is expected to make the country warmer and drier in

the future (Bazrafshan 2017, Rahimi et al. 2013, Vaghefi et al. 2019).

There are a large number of studies that connect large-scale atmospheric-oceanic phenomena (i.e. teleconnections) to the occurrence of droughts/floods in different parts of the country in different seasons of the year. Research in this context suggests that four teleconnections, namely El Niño-Southern Oscillation (ENSO), North Atlantic Oscillation (NAO), Arctic Oscillation (AO), and North Caspian Sea Pattern (NCP), have major effects on climate variability in Iran, as discussed below:

i. ENSO: In the majority of the country, autumn precipitation increases during the positive phase of ENSO (i.e. El Niño), and winter and summer precipitation decreases. In addition, a severe La Niña (the negative phase of ENSO) intensify the probability of 
ii. NAO: The strong NAO is associated with high precipitation and low temperature in winter in most region of Iran (Moradi 2004).

iii. AO: Air temperature in winter is negatively associated with AO in most parts of Iran.

This means that the positive (negative) air temperature anomalies are correlated with the negative (positive) AO phases (Ghasemi and Khalili 2006).

iv. NCP: NCP's positive (negative) phase accords with the increase (decrease) in Iran's winter precipitation. The colder (warmer) than normal winter temperature in Iran is consistent with the positive (negative) phase of NCP (Ghasemi and Khalili 2008).

\subsection{Data}

In this study, three different datasets were used:

i. Local-scale climate data, measuring at weather stations, were employed to calculate drought indices. The monthly precipitation and air temperature data recorded at 32 weather stations (Fig. 1) in Iran cover a common period from 1964 to 2014. The data were procured from IR of Iran Meteorological Organization (IRIMO). Preliminary assessments of the data showed that 18 out of 32 stations had no missing values during the record period. Missing data of a given station (i.e. the base station) were filled using a regression equation between the base station and a neighboring station of complete data that was strongly correlated with the base station (Sattari et al. 2017).

ii. Large-scale climate indices (teleconnections), occurring at far distances over oceans, were used as covariates within the non-stationary models. The monthly data of ENSO,

NAO, and AO were downloaded from the webpage of NOAA

(https://www.ncdc.noaa.gov/teleconnections/) and those of NCP from the webpage of CRU (https://crudata.uea.ac.uk/cru/data/ncp/ncp.dat).

iii. Normalized Difference Vegetation Index (NDVI) data, being the product of NOAA 
used to monitor the drought occurrence in vegetation cover. The temporal resolution of

the product is twice a month (each 15 days) with a $0.083^{\circ}$ by $0.083^{\circ}$ spatial grid

resolution. The data covered the period of July 1981 to December 2015 (Pinzon and

Tucker 2014), and are available from the webpage

\subsection{Methods}

\subsubsection{Standardized Precipitation Evapotranspiration Index (SPEI)}

The Standardized Precipitation Evapotranspiration Index (SPEI), as a climatic drought index,

follow:

i. Calculation of a simple climatic water balance according to the following equation:

$D_{i}=P_{i}-A E D_{i}$

where $D_{i}$ is the difference between precipitation $\left(P_{i}\right)$ and atmospheric evaporative

ii. Selection of timescale: In this research, SPEI was calculated at 12-month timescale due

to the management of Iran's water resources on the water-year scale (i.e. from October

Wilhite 1999).

iii. Moving aggregation of consecutive $D$-values at a given timescale:

$$
x_{t, k}=\sum_{i=t-k+1}^{t} D_{i} \quad \text { for } t \geq k
$$


where $x_{t, k}$ is the cumulative $D$-values of the $k$-month timescale (here $k=12$ ) at the time $t$

$(t=1,2, \ldots, n)$ and is called the $x$-series, hereafter.

iv. Fitting a suitable probability distribution function to the $x$-series. According to the studies of Vicente-Serrano et al. (2010), the three-parameter log-logistic distribution has the flexibility to fit appropriately the $x$-series worldwide, with assuming the temporal stationarity of the series. The mathematical form of the probability density function of the above-mentioned distribution is expressed as below:

$f(x)=\frac{\beta}{\alpha}\left(\frac{x-\gamma}{\alpha}\right)^{\beta-1}\left[1+\left(\frac{x-\gamma}{\alpha}\right)^{\beta}\right]^{-2}$

where $\alpha, \beta$ and $\gamma$ are the parameters of scale, shape and location of the distribution, 286 respectively, and $x$ is the cumulative series of $D$-values at a given timescale. The parameters of this function are obtained using the L-moment method (Hosking, 1990) from the following equations:

$\beta=\frac{2 w_{1}-w_{0}}{6 w_{1}-w_{0}-6 w_{2}}$

$\alpha=\frac{\left(w_{0}-2 w_{1}\right) \beta}{\Gamma\left(1+\frac{1}{\beta}\right) \Gamma\left(1-\frac{1}{\beta}\right)}$

$\gamma=w_{0}-\alpha \Gamma\left(1+\frac{1}{\beta}\right) \Gamma\left(1-\frac{1}{\beta}\right)$

where $\Gamma($.$) is the Gamma function and w_{0}, w_{1}$ and $w_{2}$ are the probability weighting moments calculating from the following equation:

$w_{s}=\frac{1}{n} \sum_{m=1}^{n}\left(1-F_{m}\right)^{s} D_{m}$

where $F$ is the empirical distribution function, $n$ is the total number of data, $m$ is the rank of 296 data in the ascending order, and $s$ is the moment order, and here it is considered zero, 1 , and 2 to calculate the terms $w_{0}, w_{1}$ and $w_{2}$, respectively, in Eq. (4-6). The value of $F$ is calculated from the empirical function (Hosking 1990), as below:

$F_{m}=\frac{m-0.35}{n}$ 
The log-logistic cumulative distribution function of $x$ is defined by the expression:

$$
F(x)=\left[1+\left(\frac{\alpha}{x-\gamma}\right)^{\beta}\right]^{-1}
$$

v. Calculation of SPEI: The cumulative probability of any value of $x$ (i.e. $F(x)$ ) is transformed to the standard normal variate (with mean zero and variance one), socalled SPEI. Using the approximation of Abramowitz and Stegun (1965), the cumulative probability is transformed to the standard normal variate (i.e. the SPEI equation), as follows:

$S P E I=W-\frac{C_{0}+C_{1} W+C_{2} W^{2}}{1+d_{1} W+d_{2} W^{2}+d_{3} W^{3}}$

in which,

$W=\sqrt{-2 \ln (P)} \quad$ for $\quad P \leq 0.5$

and $P=1-F(x)$. If $P>0.5,1-P$ is substituted for $P$ in Eq. (11). The constants in the

SPEI equation are:

$$
\begin{aligned}
& C_{0}=2.515517, \quad C_{1}=0.802853, \quad C_{2}=0.010328 \\
& d_{1}=1.432788, \quad d_{2}=0.189269, \quad d_{3}=0.001308
\end{aligned}
$$

Since the traditional SPEI is calculated under stationary condition; henceforth, we call

it the Stationary SPEI (SSPEI). The SSPEI classification is described in Table 1. The negative values of SSPEI demonstrate the dry periods (droughts) and the positive values of SSPEI imply the wet periods.

\subsubsection{Non-stationary SPEI (NSPEI)}

The methodology of Non-stationary Standardized Precipitation Evapotranspiration Index

(NSPEI) is presented in Fig. 2. While the SSPEI assumes all parameters of the log-logistic

distribution fitted to the $x$-series (the cumulative $D$-values) are constant (stationary), the

NSPEI fits an optimal non-stationary model to the series. The non-stationary statistical model 
external covariates. The external covariates selected in this study are the time variable and the

climate indices influencing the precipitation and air temperature in Iran, namely ENSO,

NAO, AO, and NCP (Alizadeh-Choobari et al. 2018, Dezfuli et al. 2010, Ghasemi and

Khalili 2006, 2008). Many researchers believe that climate change, in most probable case,

changes the average of climate variables in the regional or global scale (Cheng and

AghaKouchak 2014, Kwon and Lall 2016, Li et al. 2015, Russo et al. 2013, Wang et al.

2015). The non-stationary models used in the study assume that the location parameter of log-logistic distribution is a multivariable function of the covariates as below:

$\gamma(t)=a_{0}+a_{1} t+b_{1} C_{1}(t-l)+\cdots+b_{m} C_{m}(t-l)$

where $\gamma(t)$ is the location parameter at time $t, a_{0}$ is the intercept, $b_{1}, \ldots, b_{m}$ are the regression coefficients, $C_{1}(t-l), \ldots, C_{m}(t-l)$ are the climate indices at time $t-l$ in which $l$ is the lagbe constant. The optimal combination of the variables in Eq. (12) for each month of the year at 12-month timescale is selected using the forward selection method in the framework of Generalized Additive Models in Location, Scale and Shape (GAMLSS) algorithm (Rigby and Stasinopoulos 2005). In this study, GAMLSS is applied to model a non-stationary loglogistic distribution using a (semi) parametric relationship between the location parameter $\gamma(t)$ and each combination of the covariates through the monotonic link function $(g()$.$) , as$ below:

$$
g(\gamma)=X \alpha+\sum_{j=1}^{J} Z_{j}\left(\beta_{j}\right)
$$

where $\alpha$ is a parameter vector of size $J, X$ is a fixed, known design vector of size $J, \beta_{j}$ is a vector of random effects parameters having normal distribution, $Z_{j}$ is a non-parametric 
Eq. (13) is evaluated for different combinations from 1 to 5 variables corresponding to

the five covariates used in this study. The best non-stationary model is one with the least AIC

In order to calculate NSPEI, the cumulative probability corresponding to any values of the $x$-series is estimated from the non-stationary log-logistic distribution, and then, is transformed inversely to the standard normal variate (here called NSPEI). Classification of 359 the NSPEI is like the SSPEI, as shown in Table 1. The NSPEI values less than zero imply the dry conditions (droughts) and those equal to or more than zero indicate the wet conditions.

\subsubsection{Vegetation Condition Index}

The Vegetation Condition Index (VCI), which was firstly proposed by Kogan (1995), is a

$V C I=\frac{N D V I-N D V I_{\min }}{N D V I_{\max }-N D V I_{\min }} \times 100$

where $N D V I$ is the smoothed monthly NDVI, and $N D V I_{\min }$ and $N D V I_{\max }$ are the multi-year

minimum and maximum NDVI values, respectively, in each grid cell in each month of the vegetation. Unlike the NDVI which represents the compound effect of weather and ecology in drought monitoring, the VCI is able to separate the ecology component from the NDVI data and to quantify only the effect of meteorological droughts on vegetation (Rahimzadeh 
In this study, the VCI was calculated from the NDVI averaged over a $3 \times 3$ window,

including the nine pixels around the position of each weather station (Rahimzadeh Bajgiran et

al. 2008). Then, a 12-month moving average method, like the SSPEI and NSPEI, was applied

to the VCI series. A drought event in vegetation happens when the VCI be less than $40 \%$

(Ghaleb et al. 2015). Temporal variations in vegetation over the study area were assessed in

association with SSPEI and NSPEI to determine the necessity of incorporating the nonstationary framework into the SPEI calculations.

\subsubsection{The Orientation and Magnitude of Trend}

A nonparametric Mann-Kendall (MK) statistical test (Kendall 1970, Mann 1945) is employed

to evaluate the trend orientation in $\mathrm{P}, \mathrm{AED}$, and $x$-series at all stations of interest. Considering

$Z= \begin{cases}\frac{S-1}{\sqrt{\operatorname{Var}(S)}} & , S>0 \\ 0, & S=0 \\ \frac{S+1}{\sqrt{\operatorname{Var}(S)}} & , S<0\end{cases}$

where $S$ is sum of the sign function values according to the following formula:

$S=\sum_{i=1}^{n-1} \sum_{j=i+1}^{n} \operatorname{sgn}\left(u_{i}-u_{j}\right)$

and $\operatorname{Var}(S)$ is the variance of $S$ which is defined as:

$\operatorname{Var}(S)=\frac{1}{18}\left[n(n-1)(2 n+5)-\sum_{p-1}^{g} t_{p}\left(t_{p}-1\right)\left(2 t_{p}+5\right)\right]$

where $g$ is the number of tied groups and $t_{p}$ is the number of observations in the $p$ th group.

The no trend hypothesis is rejected if $|Z|>Z_{1-\alpha / 2}$ in which $Z_{1-\alpha / 2}$ follows the standard normal variate at the significance level of $\alpha$. A positive (negative) significant value of $Z$ indicates an upward (downward) monotonic trend. Note that the lag-1 autocorrelations in data series were removed prior the data to be further analyzed for trend detection, according to the approaches presented in Hamed and Ramachandra Rao (1998) and Yue et al. (2002). 
In addition to the orientation of trend, the magnitude of the trend in data series is

estimated using the Sen's slope estimator (Sen 1968). The median of slopes (b) for any two

time points of data is determined by the following equation:

$b=\operatorname{Median}\left(\frac{u_{j}-u_{i}}{j-i}\right), \quad 1 \leq i<j \leq n$

\section{Results and Discussions}

\subsection{Trend Analysis}

Table 3 shows the orientation and magnitude of trends in precipitation $(\mathrm{P})$, atmospheric 402 evaporative demand (AED), and P-AED (i.e. D). As shown in this table, using the MK test, 403 $59.4 \%$ and $6.3 \%$ of the stations detected the significant negative and positive trends, respectively, in precipitation data at the 5\% significance level. The MK test revealed more 405 significant positive trends $(50.0 \%$ of stations $)$ than negative trends $(40.6 \%$ of stations) in 406 AED. While some stations (e.g. Ahvaz, Birjand, and Gorgan) experienced a downward trend 407 in both $\mathrm{P}$ and AED, some other stations (e.g. Esfahan and Tehran-Mehrabad) indicated an 408 upward trend in both of the above variables. In several stations, the trend orientation in $\mathrm{P}$ was 409 opposite to that in AED (for example, at Bandar Anzali, while P showed a downward trend, AED indicated an upward trend). The magnitude of the trend across the studied stations ranged from -2.78 (Gorgan) to 1.07 (Esfahan) mm/decade for P, and from -3.32 (Shahrekord) to 9.15 (Abadan) $\mathrm{mm} /$ decade for AED.

With respect to $\mathrm{P}$ and AED as the two components of $\mathrm{D}$, the magnitude of trends for both variables determines the direction of the temporal trend in D. According to Table 3, the trend magnitude of AED in most stations are larger than those of P; thus, the direction and slope of the trend in $\mathrm{D}$ is predicted to be more determined by AED than by $\mathrm{P}$. This is 
seen in Fig. 3. It can therefore be said with great confidence that a downward (upward) trend

in AED leads to an upward (downward) trend in D. Referring to Table 3, it can be found that

the MK test reported significant positive and negative trends in $18.7 \%$ and $59.4 \%$ of the

stations, respectively. These findings indicate that the water deficit has intensified with time

in more than half of the stations of interest. In addition, at most stations, the D series are non-

stationary, and thus the development of a drought index that is consistent with changing

climate is necessary.

\subsection{Teleconnection between the $x$-Series and Climate Indices}

Fig. 3 displays the boxplot of the Spearman correlation coefficients between the 12-month

aggregated D-values (i.e. the $x$-series) and each of the four selected climate indices (ENSO,

$\mathrm{AO}, \mathrm{NCP}$, and NAO) used in this study for the 0- to 12-month lag-times. As can be seen in

the figure, while the $x$-series has negative correlations with ENSO, its correlations with the

other three climate indices are mostly positive. The $x$-series have significant correlations with

ENSO in more than half of the stations for the 0- to 1-month lag-times and, with the lag-times

increasing to 12 months, the correlations become non-significant. In a number of stations,

five months, shorter than eight months, and 0-1 and longer than seven months, respectively.

The results showed the relative significance of ENSO, compared to the other three indices, in

\subsection{Selection of the Optimal Non-stationary Models}

Table 4 shows the step-by-step forward selection of the covariates (namely t, ENSO, AO,

$\mathrm{NCP}$, and NAO) for estimation of the location parameter of log-logistic distribution at the 
important variable in the first position and the other variables occupy the second to fifth

position. In this selection method, five non-stationary models with a combination of 1 to 5

variables were constructed to estimate the location parameter at the studied stations. For

example, as shown in Table 4, at Abadan station, according to the AIC values in the steps (1)-

(5), the bivariate model with covariates $t$ and $N C P(t-5)$ has the lowest AIC value and is considered as the best non-stationary model to estimate the location parameter. However, the

univariate model in step (1), which has only the $t$-covariate, has been selected as the optimal

model because the difference between the AIC of the optimal model and that of the best

model is not significant and the number of variables used in the optimal model is less than the

best model. Also, the selected optimal model has $\mathrm{AIC}=720$ that is less than the $\mathrm{AIC}$ of the

stationary model (743.3). The non-stationary optimal models outperformed the stationary

model at almost all stations except Kerman station. This result is valid for all other sub-

Table 5 shows the mathematical formulae of the optimal non-stationary models to estimate the location parameter of log-logistic distribution at the studied stations for the 12month sub-period of October-September. As mentioned above, a time-dependent model is 460 sufficient to model the non-stationarity of the location parameter at Abadan station (\#1). If time is a strong covariate in the model, it should also be verified by the non-parametric 462 Mann-Kendall (MK) test. As can be seen in Table 5, the MK statistic at this station is 463 significant at the $99 \%$ confidence level. The negative slope of $t$ in the optimal model $\left(\gamma_{t}=\right.$ 464 $2949.7-10.9 t$ ) and the negative value of the MK statistic, both of which suggest a clear downward trend in the $x$-series at the station. As a general rule, it may be concluded that the larger the MK statistic, the stronger the effect of time covariate on non-stationarity in the location parameter (Bazrafshan and Hejabi 2018). 
Fig. 5 compares the number of times that the five covariates were used in the optimal

non-stationary models across the studied stations. ENSO had the highest frequency, and

that the importance of $\mathrm{t}$ in the optimal non-stationary models was higher than NAO and AO.

This result confirmed the findings of the other researchers (Golian et al. 2015, Nazemosadat

and Cordery 2000, Nazemosadat and Ghasemi 2004) who emphasized the importance of

ENSO on the precipitation pattern over Iran.

\subsection{Comparison of SSPEI and NSPEI}

\subsubsection{Temporal Variations}

The two drought indices SSPEI and NSPEI were calculated on a 12-month timescale at all

stations of interest. The temporal behaviors of these two indices for the sample stations in the

climates were compared, as shown in Fig. 6. According to the figure, there was a slight

difference between the time series of SSPEI and NSPEI in the extreme climates (arid and

the semi-arid and Mediterranean climates. Especially in Tabriz station (with semi-arid 
In-depth analyzes of the results of other stations showed (figure not presented)

wherever the covariates had a clear impact on P and AED (the two components needed for

the calculation of the indices), there was a substantial difference between SSPEI and NSPEI.

As a result, the difference between the time series of SSPEI and NSPEI had no association

with the stations' climate in the study area.

\subsubsection{Assessment of Drought Severity and Duration}

Temporal variations of drought/wet events in terms of duration and severity (for the drought index $<0$ ) have been compared between SSPEI and NSPEI, as shown in Fig. 7 for all chosen stations during 1964 - 2014. On the basis of SSPEI, the figure clearly shows the occurrence

after 2004. For the decades before 1990s, although a dominant pattern of drought/wet period

The drought severity-duration (S-D) relationships related to the two indices SSEPI and 
decrease. In addition, the slopes of the S-D relationships are reduced. In other words, for a given drought duration, the severity of drought in arid climates is higher than that in semi-

Comparison between SSPEI and NSPEI shows that the slope of S-D equations in the not statistically significant. In most stations, the slope of the S-D relationships for NSPEI is greater than SSPEI. Fig. 8e is drawn on the basis of all drought durations and severities for NSPEI is slightly larger than SSPEI. However, a comparison of the S-D values in the same figure shows that SSPEI reports more severe and prolonged droughts than NSPEI over the record period.

\subsubsection{Frequency Analysis of Drought Classes}

Fig. 9 shows the frequency of different drought and wet period classes for the two indices

SSPEI and NSPEI in the sample stations representing different climates of Iran. As per this

figure, there is a slight difference between SSPEI and NSPEI in terms of the frequency of (Fig. 9b) and Mediterranean (Fig. 9c) climates, these differences are quite obvious in some classes. For example, in the semi-arid station of Tabriz (Fig. 9b), the frequencies of severe and extreme classes (mild and moderate classes) of drought for NSPEI are higher (lower) than those for SSPEI, but in the Mediterranean station of Gorgan (Fig. 9c) the results are 
However, the frequencies for mild, medium and severe drought classes of SSPEI are higher than those of NSPEI.

\subsubsection{Spatiotemporal Analysis of Drought and Wet Events}

The average, minimum, and maximum time series of SSPEI and NSPEI are displayed in Fig. 546

10, which are calculated across the studied stations based on the water-year (October-

September) data. As shown in the figure, both indices have an upward trend from1964-1993

and a downward trend from 1994 onwards, with a more decreasing slope for SSPEI

compared to NSPEI. While SSPEI identifies several drought periods including 1964-1966,

1969-1970, 1972-1973, 1988-1990, 1998-2003, and 2005-2014, NSPEI detects 1964-1966,

1969-1970, 1972, 1976-77, 1983, 1988-1990, 1998-2003, 2005, 2007-2008, and 2013 as

drought periods. The similar drought periods were also reported in Bazrafshan's et al. (2017),

based on the Iran precipitation data over the past hundred years. The important point is that

the long-term drought period of 2005-2014 identified by SSPEI has been broken by NSPEI

into three smaller drought periods, namely 2005, 2007-2008, and 2013. Fig. 10 also

represents the percentage of the country drought-affected area in different months during the

period of 1964-2014. The figure shows that percentage of drought-prone areas has increased during drought periods.

Fig. 11 displays the spatiotemporal distribution of SSPEI and NSPEI over Iran during the water years (October-September) of 1964/65-2013/14. As shown in the figure, the 
based on SSPEI, the eastern half of the country experiences the above-normal conditions

according to the NSPEI results. Considering the 2010/11, the difference between the maps of

SSPEI and NSPEI is higher than 1998/99. On the basis of SSPEI, almost all regions of the

country are affected by drought in 2010/11 while NSPEI monitored the above-normal

\subsubsection{The Vegetation Response to the Drought Indicators}

Applicability of remote sensing data (such as NDVI and VCI) for drought monitoring in Iran

has been considered by several researchers (Rahimzadeh Bajgiran et al. 2008, Shamsipour et

al. 2008). The results of the studies conducted in Iran showed that the temporal and spatial

characteristics of drought could be detected and mapped using the indices derived from

the satellite images.

In this study, the response of vegetation cover to the severest drought (the 2008

compared to NSPEI. The monthly averages of VCI, SSPEI, and NSPEI throughout the

it. Although the two indicators were almost identical in terms of identifying the onset of the 
is in its lowest value, NSPEI detects a moisture signal which is very stronger than that of

SSPEI. Four months later, VCI returns to normal in response to the signal. Thus, one can

conclude the superiority of NSPEI, as a better indicator of vegetation response to

meteorological drought than SSPEI, and the necessity for the development of non-stationary

\section{Conclusion}

In this study, a Non-stationary Standardized Precipitation Evapotranspiration Index (NSPEI) was developed for reliable and robust monitoring of meteorological drought characteristics in logistic probability distribution in the mathematical structure of traditional SPEI (i.e. SSPEI).

- Due to the significant decreasing trends in precipitation $(\mathrm{P})$ and the significant increasing trends in atmospheric evaporative demand (AED) at most stations of interest, the water stress has intensified in Iran during last four decades up until 2014.

- The non-stationary log-logistic distribution fitted the water deficits/surpluses series almost all chosen stations.

- The location parameter of non-stationary log-logistic distribution mostly influenced 
importance than the other two teleconnections (i.e. NAO and AO) in simulating the

temporal variations of location parameter.

- Existing the significant temporal trends in the P minus AED series led to the major differences between the NSPEI and SSPEI series at several stations. However,

- The SSPEI monitored the drought events with durations and severities larger than those identified by NSPEI. Also, the long-term drought periods (e.g. the 1998/99-

- NSPEI identified the frequency of the extreme drought and wet events greater than SSPEI across the studied stations.

- There were clear differences between SSPEI and NSPEI in terms of the spatial maps of drought/wet events during the record period of 1964-2014.

- During the severest 2008 drought, the temporal variations of the average vegetation cover (quantified by average $\mathrm{VCI}$ ) over the studied stations were closely related to the 2008 drought characteristics in vegetation cover in terms of both the drought duration and termination.

\section{Acknowledgement}

The authors would like to thank the Iran National Science Foundation (INSF) for

Not applicable. 
Not applicable.

Consent to Publish

Not applicable.

Javad Bazrafshan: Conceptualization, Methodology, and Writing-Original draft preparation.

Majid Cheraghalizadeh: Data curation, Methodology, Investigation and Editing, 648

Visualization, Software, and Validation. Kokab Shahgholian: Investigation and Editing.

Funding

This study was funded by Iran National Science Foundation (Grant Number 96010915).

\section{Competing Interests}

The authors declare that they have no conflict of interest.

\section{Availability of data and materials}

Readers can contact authors for availability of data and materials.

References

Abramowitz, M. and Stegun, I.A. (1965) Handbook of mathematical functions with

Akaike, H. (1974) A new look at the statistical model identification. IEEE 660 Transactions on Automatic Control 19(6), 716-723. 
Alizadeh-Choobari, O., Adibi, P. and Irannejad, P. (2018) Impact of the El Niño662

Southern Oscillation on the climate of Iran using ERA-Interim data. Climate Dynamics 51(7), 663 $2897-2911$.

Allen, R.G., Pereira, L.S., Raes, D. and Smith, M. (1998) Crop Evapotranspiration. 665 Guidelines for Computing Crop Water Requirements, p. 300p.

Asadi Zarch, M.A., Sivakumar, B. and Sharma, A. (2015) Droughts in a warming 667 climate: A global assessment of Standardized precipitation index (SPI) and Reconnaissance 668 drought index (RDI). Journal of Hydrology 526, 183-195.

Bateni, M.M., Behmanesh, J., Michele, C.D., Bazrafshan, J. and Rezaie, H. (2018) 670

Composite Agrometeorological Drought Index Accounting for Seasonality and 671 Autocorrelation. Journal of Hydrologic Engineering 23(6), 04018020.

Bazrafshan, J. (2017) Effect of Air Temperature on Historical Trend of Long-Term 673 Droughts in Different Climates of Iran. Water Resources Management.

Bazrafshan, J. and Hejabi, S. (2018) A Non-Stationary Reconnaissance Drought Index 675 (NRDI) for Drought Monitoring in a Changing Climate. Water Resources Management 676 32(8), 2611-2624.

Bazrafshan, J., Hejabi, S. and Eslamian, S. (2017) Handbook of Drought and Water 678 Scarcity S., E. and F., E. (eds), pp. 167-188, Francis and Taylor, CRC Press, USA.

Bazrafshan, J., Hejabi, S. and Rahimi, J. (2014) Drought Monitoring Using the 680 Multivariate Standardized Precipitation Index (MSPI). Water Resources Management 28(4), 681 $1045-1060$

Beguería, S., Vicente-Serrano, S.M., Reig, F. and Latorre, B. (2014) Standardized 683 precipitation evapotranspiration index (SPEI) revisited: parameter fitting, evapotranspiration 684 models, tools, datasets and drought monitoring. International Journal of Climatology 34(10), 685 3001-3023. 
Bhardwaj, K., Shah, D., Aadhar, S. and Mishra, V. (2020) Propagation of 687 meteorological to hydrological droughts in India. Journal of Geophysical Research: 688 Atmospheres n/a(n/a), e2020JD033455.

Burnham, K.P. and Anderson, D.R. (2002) Model selection and multimodel inference:

Byun, H.-R. and Wilhite, D.A. (1999) Objective Quantification of Drought Severity

Cheng, L. and AghaKouchak, A. (2014) Nonstationary Precipitation Intensity-

De Planhol, X. (2012) Famines, in: Encyclopedia Iranica, IX/2, pp. 203-206.

Dezfuli, A.K., Karamouz, M. and Araghinejad, S. (2010) On the relationship of 698 regional meteorological drought with SOI and NAO over southwest Iran. Theoretical and 699 Applied Climatology 100(1), 57-66.

Edossa, D.C., Woyessa, Y.E. and Welderufael, W.A. (2014) Analysis of Droughts in 701 the Central Region of South Africa and Their Association with SST Anomalies. International 702 Journal of Atmospheric Sciences 2014, 508953.

Ghaleb, F., Mario, M. and Sandra, A.N. (2015) Regional Landsat-Based Drought 704 Monitoring from 1982 to 2014. Climate 3(3), 563-577.

Ghasemi, A.R. and Khalili, D. (2006) The influence of the Arctic Oscillation on 706 winter temperatures in Iran. Theoretical and Applied Climatology 85(3), 149-164.

Ghasemi, A.R. and Khalili, D. (2008) The effect of the North Sea-Caspian pattern 708 (NCP) on winter temperatures in Iran. Theoretical and Applied Climatology 92(1), 59-74.

Golian, S., Mazdiyasni, O. and AghaKouchak, A. (2015) Trends in meteorological 710 and agricultural droughts in Iran. Theoretical and Applied Climatology 119(3), 679-688. 
Guenang, G.M. and Kamga, F.M. (2014) Computation of the Standardized

Precipitation Index (SPI) and Its Use to Assess Drought Occurrences in Cameroon over

Recent Decades. Journal of Applied Meteorology and Climatology 53(10), 2310-2324.

Hamed, K.H. and Ramachandra Rao, A. (1998) A modified Mann-Kendall trend test

Hernandez, E.A. and Uddameri, V. (2014) Standardized precipitation evaporation

index (SPEI)-based drought assessment in semi-arid south Texas. Environmental Earth

Hosking, J.R.M. (1990) L-Moments: Analysis and Estimation of Distributions Using

Linear Combinations of Order Statistics. Journal of the Royal Statistical Society. Series B

Huang, S., Li, P., Huang, Q., Leng, G., Hou, B. and Ma, L. (2017) The propagation

IPCC (2014) Climate Change 2014: Synthesis Report. Contribution of Working

Change [Core Writing Team, R.K. Pachauri and L.A. Meyer (eds.)]. IPCC, Geneva,

Kang, L. and Jiang, S. (2019) Bivariate Frequency Analysis of Hydrological Drought

Using a Nonstationary Standardized Streamflow Index in the Yangtze River. Journal of

Kendall, M.G. (1970) Rank Correlation Methods, Griffin: London.

Khalili, A. (1997) Synthesis proceeding of integrated water plan of Iran. Jamab 
Khalili, A. and Rahimi, J. (2014) High-resolution spatiotemporal distribution of 736 precipitation in Iran: a comparative study with three global-precipitation datasets. Theoretical and Applied Climatology 118(1), 211-221.

Khalili, A. and Rahimi, J. (2018) The Soils of Iran. Roozitalab, M.H., Siadat, H. and 739 Farshad, A. (eds), pp. 19-33, Springer International Publishing, Cham.

Kogan, F.N. (1995) Application of vegetation index and brightness temperature for 741 drought detection. Advances in Space Research 15(11), 91-100.

Kwon, H.-H. and Lall, U. (2016) A copula-based nonstationary frequency analysis for 743 the 2012-2015 drought in California. Water Resources Research 52(7), 5662-5675.

Li, J.Z., Wang, Y.X., Li, S.F. and Hu, R. (2015) A Nonstationary Standardized 745 Precipitation Index incorporating climate indices as covariates. Journal of Geophysical 746 Research: Atmospheres 120(23), 12,082-012,095.

Mann, H.B. (1945) Nonparametric Tests Against Trend. Econometrica 13(3), 245259.

Mavromatis, T. (2007) Drought index evaluation for assessing future wheat 750 production in Greece. International Journal of Climatology 27(7), 911-924.

McKee, T.B., Doeskin, N.J. and Kleist, J. (1993) The relationship of drought 752 frequency and duration to time scales, pp. 179-184, American Meteorological Society, 753 Anaheim, CA.

Mishra, A.K. and Singh, V.P. (2010) A review of drought concepts. Journal of 755 Hydrology 391(1), 202-216.

Moradi, H.R. (2004) North atlantic oscilation index and its effect on climate of Iran. 757 Geographical Research Quaterly 36(48), 17-30.

Nazemosadat, M.J. and Cordery, I. (2000) On the relationships between ENSO and 759 autumn rainfall in Iran. International Journal of Climatology 20(1), 47-61. 
Nazemosadat, M.J. and Ghasemi, A.R. (2004) Quantifying the ENSO-Related Shifts

in the Intensity and Probability of Drought and Wet Periods in Iran. Journal of Climate

OFDA/CRED (2015) International Disaster Database. Université catholique de

Paulo, A.A. and Pereira, L.S. (2006) Drought Concepts and Characterization. Water

Pinzon, J.E. and Tucker, C.J. (2014) A Non-Stationary 1981-2012 AVHRR NDVI3g

Rahimi, J., Ebrahimpour, M. and Khalili, A. (2013) Spatial changes of Extended De

Rahimzadeh Bajgiran, P., Darvishsefat, A.A., Khalili, A. and Makhdoum, M.F.

Rashid, M.M. and Beecham, S. (2019) Development of a non-stationary Standardized

Raziei, T., Saghafian, B., Paulo, A.A., Pereira, L.S. and Bordi, I. (2008) Spatial

Rigby, R.A. and Stasinopoulos, D.M. (2005) Generalized additive models for 782 location, scale and shape. Journal of the Royal Statistical Society: Series C (Applied 
Russo, S., Dosio, A., Sterl, A., Barbosa, P. and Vogt, J. (2013) Projection of 785 occurrence of extreme dry-wet years and seasons in Europe with stationary and nonstationary $\quad 786$ Standardized Precipitation Indices. Journal of Geophysical Research: Atmospheres 118(14), 787 7628-7639.

Sattari, M.-T., Rezazadeh-Joudi, A. and Kusiak, A. (2017) Assessment of different 789 methods for estimation of missing data in precipitation studies. Hydrology Research 48(4), 790 1032-1044.

Schwarz, G. (1978) Estimating the Dimension of a Model. The Annals of Statistics 792 $6(2), 461-464$

Sen, P.K. (1968) Estimates of the Regression Coefficient Based on Kendall's Tau. 794 Journal of the American Statistical Association 63(324), 1379-1389.

Şen, Z. (2015) Applied Drought Modeling, Prediction, and Mitigation, pp. 205-274, 796 Elsevier, Boston.

Serinaldi, F. and Kilsby, C.G. (2015) Stationarity is undead: Uncertainty dominates 798 the distribution of extremes. Advances in Water Resources 77, 17-36.

Shamsipour, A.A., AlaviPanah, S.K., Mohammadi, H., Azizi, A. and Khoshakhlagh, 800 F. (2008) An analysis of drought events for central plains of Iran through an employment of 801 NOAA-AVHRR data. Desert 13(2), 105-115.

Stasinopoulos, D.M., Rigby, R.A. and Akantziliotou, C. (2008) Instructions on how to 803 use the GAMLSS package in R, 2nd edn. STORM Research Centre, London Metropolitan 804 University, London.

Thornthwaite, C.W. (1948) An Approach toward a Rational Classification of Climate. 806 Geographical Review 38(1), 55-94. 
Tirivarombo, S., Osupile, D. and Eliasson, P. (2018) Drought monitoring and 808 analysis: Standardised Precipitation Evapotranspiration Index (SPEI) and Standardised 809 Precipitation Index (SPI). Physics and Chemistry of the Earth, Parts A/B/C 106, 1-10.

Vaghefi, S.A., Keykhai, M., Jahanbakhshi, F., Sheikholeslami, J., Ahmadi, A., Yang,

Van Lanen, H.A.J. (2006) Drought propagation through the hydrological cycle. 814

Demuth, S., Gustard, A., Planos, E., Scatena, F. and Servat, E. (eds), pp. 122-127, IAHS 815

Press, Wallingford, UK.

Van Loon, A.F. (2015) Hydrological drought explained. Wiley Interdisciplinary

Vicente-Serrano, S.M., Beguería, S. and López-Moreno, J.I. (2010) A Multiscalar

Drought Index Sensitive to Global Warming: The Standardized Precipitation

Wang, Y., Duan, L., Liu, T., Li, J. and Feng, P. (2020) A Non-stationary Standardized

Streamflow Index for hydrological drought using climate and human-induced indices as covariates. Science of The Total Environment 699, 134278.

Wang, Y., Li, J., Feng, P. and Hu, R. (2015) A Time-Dependent Drought Index for

Wilhite, D.A. (2000) Drought: A Global Assessment,, Routledge, London.

Wilhite, D.A. and Glantz, M.H. (1985) Understanding: the Drought Phenomenon: The 
Yue, S., Pilon, P., Phinney, B. and Cavadias, G. (2002) The influence of 831 autocorrelation on the ability to detect trend in hydrological series. Hydrological Processes 16(9), 1807-1829.

Zarei, A.R. and Mahmoudi, M.R. (2020) Assessment of the effect of PET calculation 
Table 1. Geographic and climatic characteristics of the chosen weather stations.

\begin{tabular}{|c|c|c|c|c|c|c|}
\hline \multirow{2}{*}{ \#. Station's name } & \multirow{2}{*}{$\begin{array}{l}\text { Longitude } \\
\text { (degree) }\end{array}$} & \multirow{2}{*}{$\begin{array}{l}\text { Latitude } \\
\text { (degree) }\end{array}$} & \multirow{2}{*}{$\begin{array}{l}\text { Elevation } \\
\quad(\mathbf{m})\end{array}$} & \multicolumn{2}{|c|}{ Long-term Annual Mean of } & \multirow{2}{*}{ Climate } \\
\hline & & & & $\begin{array}{l}\text { Precipitation } \\
\quad(\mathbf{m m})\end{array}$ & $\begin{array}{c}\text { Air Temperature } \\
\left({ }^{\circ} \mathrm{C}\right)\end{array}$ & \\
\hline 1. Abadan & 48.25 & 30.37 & 6.6 & 152.2 & 25.6 & Arid \\
\hline 2. Ahwaz & 48.67 & 31.33 & 22.5 & 224.6 & 26.2 & Arid \\
\hline 3. Arak & 49.77 & 34.10 & 1708 & 328.6 & 13.8 & Semi-arid \\
\hline 4. Bam & 58.35 & 29.10 & 1066.9 & 58.1 & 23.4 & Arid \\
\hline 5. Bandar Abbas & 56.37 & 27.22 & 9.8 & 169.8 & 27.1 & Arid \\
\hline 6. Bandar Anzali & 49.45 & 37.48 & -23.6 & 1774.4 & 16.3 & Very Humid \\
\hline 7. Birjand & 59.20 & 32.87 & 1491 & 162.0 & 16.8 & Arid \\
\hline 8. Bushehr & 50.82 & 28.97 & 9.0 & 243.3 & 24.8 & Arid \\
\hline 9. Esfahan & 51.67 & 32.62 & 1550.4 & 125.1 & 16.5 & Arid \\
\hline 10. Gazvin & 50.05 & 36.25 & 1279.2 & 317.9 & 14.2 & Semi-arid \\
\hline 11. Gorgan & 54.40 & 36.90 & 0.0 & 575.8 & 17.7 & Mediterranean \\
\hline 12. Kerman & 56.97 & 30.25 & 1753.8 & 138.5 & 17.1 & Arid \\
\hline 13. Kermanshah & 47.15 & 34.35 & 1318.6 & 444.8 & 14.9 & Semi-arid \\
\hline 14. Khorramabad & 48.28 & 33.43 & 1147.8 & 493.5 & 17.3 & Semi-arid \\
\hline 15. Khoy & 44.97 & 38.55 & 1103 & 292.2 & 12.6 & Semi-arid \\
\hline 16. Mashhad & 59.63 & 36.27 & 999.2 & 250.4 & 14.4 & Semi-arid \\
\hline 17. Oroomieh & 45.05 & 37.67 & 1328 & 330.0 & 11.1 & Semi-arid \\
\hline 18. Ramsar & 50.67 & 36.91 & -20.0 & 1216.3 & 16.1 & Very Humid \\
\hline 19. Rasht & 49.62 & 37.32 & -8.6 & 1338.7 & 16.2 & Very Humid \\
\hline 20. Sabzevar & 57.65 & 36.20 & 972.0 & 189.4 & 17.7 & Arid \\
\hline 21. Saghez & 46.27 & 36.25 & 1522.8 & 483.9 & 12.0 & Semi-arid \\
\hline 22. Sanandaj & 47.00 & 35.33 & 1373.4 & 443.8 & 14.2 & Semi-arid \\
\hline 23. Shahrekord & 50.85 & 32.28 & 2048.9 & 331.1 & 12.3 & Semi-arid \\
\hline 24. Shahroud & 54.95 & 36.42 & 1349.1 & 157.1 & 14.8 & Arid \\
\hline 25. Shiraz & 52.60 & 29.53 & 1484.0 & 317.5 & 18.1 & Semi-arid \\
\hline 26. Tabriz & 46.28 & 38.08 & 1361.0 & 282.3 & 12.4 & Semi-arid \\
\hline 27. Tehran Mehrabad & 51.32 & 35.68 & 1190.8 & 234.0 & 17.5 & Arid \\
\hline 28. Torbat Heydarieh & 59.22 & 35.27 & 1450.8 & 259.5 & 14.7 & Semi-arid \\
\hline 29. Yazd & 54.28 & 31.90 & 1237.2 & 56.5 & 19.6 & Arid \\
\hline 30. Zabol & 61.48 & 31.03 & 489.2 & 55.8 & 22.6 & Arid \\
\hline 31. Zahedan & 60.88 & 29.47 & 1370.0 & 80.2 & 18.7 & Arid \\
\hline 32. Zanjan & 48.48 & 36.68 & 1663.0 & 308.0 & 11.4 & Semi-arid \\
\hline
\end{tabular}


Table 2. Description of the SSPEI/NSPEI classes (Edossa et al. 2014).

\begin{tabular}{cl}
\hline SSPEI/NSPEI Classes & Description \\
\hline$\geq 2.00$ & Extreme wet \\
1.50 to 1.99 & Severe wet \\
1.00 to 1.49 & Moderate wet \\
0.00 to 0.99 & Mild wet \\
-0.99 to 0.00 & Mild drought \\
-1.00 to -1.49 & Moderate drought \\
-1.50 to -1.99 & Severe drought \\
$\leq-2.00$ & Extreme drought \\
\hline
\end{tabular}


Table 3. The Mann-Kendall (MK) statistics, their corresponding p-values, and the Sen's slope (SS)

estimators for precipitation $(P)$, atmospheric evaporative demand (AED), and D=P-AED at the 887 stations of interest for 12-month timescale.

\begin{tabular}{|c|c|c|c|c|c|c|c|c|c|}
\hline \multirow[b]{2}{*}{ Station } & \multicolumn{3}{|c|}{$\mathbf{P}$} & \multicolumn{3}{|c|}{ AED } & \multicolumn{3}{|c|}{ D=P-AED } \\
\hline & MK & p-value & $\begin{array}{c}\text { SS } \\
\text { (mm/decade) }\end{array}$ & MK & p-value & $\begin{array}{c}\text { SS } \\
\text { (mm/decade) }\end{array}$ & MK & p-value & $\begin{array}{c}\text { SS } \\
\text { (mm/decade) }\end{array}$ \\
\hline Abadan & 0.20 & 0.840 & 0.01 & 16.67 & 0.000 & 9.15 & -15.38 & 0.000 & -9.07 \\
\hline Ahwaz & -2.27 & 0.020 & -0.41 & -5.25 & 0.000 & -3.14 & 4.70 & 0.000 & 3.12 \\
\hline Arak & -7.73 & 0.000 & -1.36 & 6.38 & 0.000 & 0.74 & -8.07 & 0.000 & -1.96 \\
\hline Bam & -3.70 & 0.000 & -0.23 & 10.80 & 0.000 & 4.55 & -11.02 & 0.000 & -4.54 \\
\hline Bandar Abbas & -0.09 & 0.930 & 0.00 & -6.49 & 0.000 & -3.20 & 5.11 & 0.000 & 3.03 \\
\hline Bandar Anzali & -1.88 & 0.060 & -1.26 & 12.32 & 0.000 & 1.27 & -3.68 & 0.000 & -2.49 \\
\hline Birjand & -3.23 & 0.000 & -0.38 & -4.58 & 0.000 & -0.80 & 1.93 & 0.054 & 0.42 \\
\hline Bushehr & 0.88 & 0.380 & 0.20 & 18.83 & 0.000 & 5.53 & -13.09 & 0.000 & -5.10 \\
\hline Esfahan & 9.63 & 0.000 & 1.07 & 17.10 & 0.000 & 1.91 & -5.15 & 0.000 & -0.82 \\
\hline Gazvin & 1.60 & 0.110 & 0.28 & -12.09 & 0.000 & -2.60 & 9.64 & 0.000 & 2.98 \\
\hline Gorgan & -11.38 & 0.000 & -2.78 & -9.31 & 0.000 & -1.40 & -4.29 & 0.000 & -1.34 \\
\hline Kerman & -6.36 & 0.000 & -0.57 & -2.99 & 0.003 & -0.73 & 1.66 & 0.097 & 0.44 \\
\hline Kermanshah & -8.36 & 0.000 & -1.94 & 19.13 & 0.000 & 2.66 & -14.10 & 0.000 & -4.68 \\
\hline Khorramabad & -7.04 & 0.000 & -1.89 & -6.45 & 0.000 & -2.12 & 1.30 & 0.195 & 0.51 \\
\hline Khoy & 0.07 & 0.950 & 0.01 & -0.43 & 0.665 & -0.06 & 1.53 & 0.125 & 0.33 \\
\hline Mashhad & -1.07 & 0.280 & -0.18 & 21.70 & 0.000 & 3.27 & -12.46 & 0.000 & -3.35 \\
\hline Oroomieh & -6.02 & 0.000 & -1.15 & 3.98 & 0.000 & 0.43 & -6.07 & 0.000 & -1.60 \\
\hline Ramsar & -3.24 & 0.000 & -1.98 & 13.22 & 0.000 & 1.75 & -5.31 & 0.000 & -3.48 \\
\hline Rasht & -2.72 & 0.010 & -1.42 & -6.73 & 0.000 & -0.82 & -0.74 & 0.457 & -0.43 \\
\hline Sabzevar & 1.52 & 0.130 & 0.21 & -0.03 & 0.977 & 0.00 & 0.22 & 0.827 & 0.06 \\
\hline Saghez & -6.56 & 0.000 & -1.73 & -5.56 & 0.000 & -0.57 & -3.62 & 0.000 & -1.21 \\
\hline Sanandaj & -10.11 & 0.000 & -2.60 & -11.03 & 0.000 & -1.31 & -4.12 & 0.000 & -1.23 \\
\hline Shahrekord & 0.91 & 0.360 & 0.18 & -20.27 & 0.000 & -3.32 & 13.07 & 0.000 & 3.43 \\
\hline Shahroud & -2.62 & 0.010 & -0.28 & -0.06 & 0.956 & -0.01 & -1.82 & 0.069 & -0.32 \\
\hline Shiraz & 1.12 & 0.260 & 0.30 & 21.77 & 0.000 & 3.26 & -9.35 & 0.000 & -3.06 \\
\hline Tabriz & -12.90 & 0.000 & -2.06 & 16.91 & 0.000 & 1.67 & -17.07 & 0.000 & -3.94 \\
\hline Tehran (Mehrabad) & 2.60 & 0.010 & 0.42 & 20.62 & 0.000 & 2.78 & -10.12 & 0.000 & -2.33 \\
\hline Torbat Heydarieh & -1.31 & 0.190 & -0.25 & -11.75 & 0.000 & -2.02 & 6.30 & 0.000 & 1.65 \\
\hline Yazd & -1.10 & 0.270 & -0.06 & 3.72 & 0.000 & 0.62 & -3.82 & 0.000 & -0.72 \\
\hline Zabol & -4.04 & 0.000 & -0.26 & 6.17 & 0.000 & 2.26 & -5.91 & 0.000 & -2.52 \\
\hline Zahedan & -4.42 & 0.000 & -0.34 & 20.08 & 0.000 & 3.17 & -17.05 & 0.000 & -3.52 \\
\hline Zanjan & -4.71 & 0.000 & -0.79 & -14.20 & 0.000 & -2.19 & 6.24 & 0.000 & 1.34 \\
\hline
\end{tabular}


Table 4. Forward selection of covariates for non-stationary modeling of the location parameter of log-

logistic distribution for the 12-month sub-period of October-September. nAIC indicates the Akaike

Information Criterion (AIC) for each step of the selection process of a non-stationary model. sAIC

shows the AIC for the stationary assumption of the log-logistic distribution parameters.

\begin{tabular}{|c|c|c|c|c|c|c|c|c|c|c|c|}
\hline \multirow{2}{*}{ Station } & \multicolumn{5}{|c|}{ Selected variables in Forward Selection } & \multicolumn{5}{|c|}{ nAIC } & \multirow{2}{*}{ sAIC } \\
\hline & Step(1) & Step(2) & Step(3) & Step(4) & Step(5) & Step(1) & Step(2) & Step(3) & Step(4) & Step(5) & \\
\hline Abadan & $\mathrm{t}$ & $\mathrm{NCP}(\mathrm{t}-5)$ & $\mathrm{AO}(\mathrm{t}-12)$ & $\mathrm{NAO}(\mathrm{t}-9)$ & $\mathrm{ENSO}(\mathrm{t}-12)$ & $720^{*}$ & 719.4 & 721.0 & 722.8 & 724.6 & 743.3 \\
\hline Ahwaz & $\mathrm{NAO}(\mathrm{t}-3)$ & $\mathrm{ENSO}(\mathrm{t}-8)$ & $\mathrm{AO}(\mathrm{t}-12)$ & $\mathrm{NCP}(\mathrm{t}-10)$ & $\mathrm{t}$ & 738.8 & $731.4^{*}$ & 730.2 & 730.0 & 731.5 & 748.6 \\
\hline Arak & $\operatorname{ENSO}(t)$ & $\mathrm{t}$ & $\mathrm{NCP}(\mathrm{t}-3)$ & $\mathrm{AO}(\mathrm{t})$ & $\mathrm{NAO}(\mathrm{t})$ & 649.2 & 647.4 & $646.7^{*}$ & 647.6 & 645.3 & 654.1 \\
\hline Bam & $\mathrm{t}$ & $\mathrm{ENSO}(\mathrm{t})$ & $\mathrm{NAO}(\mathrm{t}-4)$ & $\mathrm{NCP}(\mathrm{t}-1)$ & $\mathrm{AO}(\mathrm{t}-7)$ & 680.8 & 678.6* & 679.2 & 679.8 & 681.1 & 686.9 \\
\hline Bandar Abbas & $\mathrm{NAO}(\mathrm{t}-12)$ & $\mathrm{NCP}(\mathrm{t})$ & $\mathrm{t}$ & $\operatorname{ENSO}(t)$ & $\mathrm{AO}(\mathrm{t}-9)$ & 706.9 & 699.8 & $697.5^{*}$ & 697.2 & 698.0 & 717.2 \\
\hline Bandar Anzali & $\mathrm{ENSO}(\mathrm{t})$ & $\mathrm{NAO}(\mathrm{t}-11)$ & $\mathrm{NCP}(\mathrm{t})$ & $\mathrm{AO}(\mathrm{t}-1)$ & $\mathrm{t}$ & 755.9 & $753.5^{*}$ & 752.3 & 753.7 & 755.6 & 756.7 \\
\hline Birjand & $\operatorname{ENSO}(\mathrm{t}-1)$ & $\mathrm{AO}(\mathrm{t}-8)$ & NAO(t-9) & $\mathrm{NCP}(\mathrm{t}-3)$ & $\mathrm{t}$ & 616.6 & $611.9^{*}$ & 610.0 & 611.5 & 613.5 & 625.2 \\
\hline Bushehr & $\mathrm{t}$ & $\mathrm{NCP}(\mathrm{t}-8)$ & $\operatorname{ENSO}(t)$ & $\mathrm{AO}(\mathrm{t}-10)$ & $\mathrm{NAO}(\mathrm{t}-12)$ & 677.7 & $669.3^{*}$ & 669.2 & 670.1 & 670.4 & 693.8 \\
\hline Esfahan & $\mathrm{NCP}(\mathrm{t}-9)$ & $\mathrm{t}$ & $\mathrm{AO}(\mathrm{t}-8)$ & $\mathrm{NAO}(\mathrm{t}-10)$ & $\operatorname{ENSO}(t)$ & $606.5^{*}$ & 606.9 & 607.9 & 608.4 & 609.5 & 608.4 \\
\hline Gazvin & $\operatorname{ENSO}(t-1)$ & $\mathrm{t}$ & $\mathrm{AO}(\mathrm{t}-12)$ & $\mathrm{NAO}(\mathrm{t}-8)$ & $\mathrm{NCP}(\mathrm{t}-6)$ & 655.5 & $650^{*}$ & 649.9 & 649.7 & 648.7 & 663.1 \\
\hline Gorgan & $\mathrm{NCP}(\mathrm{t}-8)$ & $\mathrm{ENSO}(\mathrm{t}-11)$ & $\mathrm{t}$ & $\mathrm{AO}(\mathrm{t}-6)$ & $\mathrm{NAO}(\mathrm{t})$ & 650.9 & 649.3 & 648.5 & 648.7 & $645.6^{*}$ & 656.9 \\
\hline Kerman & $\mathrm{t}$ & $\operatorname{ENSO}(\mathrm{t}-5)$ & $\mathrm{NAO}(\mathrm{t}-7)$ & $\mathrm{AO}(\mathrm{t}-5)$ & $\mathrm{NCP}(\mathrm{t}-8)$ & 664.4 & 665.1 & 665.4 & 664.4 & 666.2 & $644.1 *$ \\
\hline Kermanshah & $\operatorname{ENSO}(t)$ & $\mathrm{NAO}(\mathrm{t})$ & $\mathrm{NCP}(\mathrm{t}-10)$ & $\mathrm{AO}(\mathrm{t}-8)$ & $\mathrm{t}$ & $637.9 *$ & 638.0 & 639.3 & 640.4 & 642.4 & 684.1 \\
\hline Khorramabad & $\operatorname{ENSO}(\mathrm{t})$ & $\mathrm{NCP}(\mathrm{t}-3)$ & $\mathrm{NAO}(\mathrm{t}-12)$ & $\mathrm{AO}(\mathrm{t}-10)$ & $\mathrm{t}$ & $685.6^{*}$ & 683.7 & 683.9 & 684.2 & 685.9 & 693.2 \\
\hline Khoy & $\mathrm{NCP}(\mathrm{t}-1)$ & $\mathrm{ENSO}(\mathrm{t})$ & $\mathrm{NAO}(\mathrm{t})$ & $\mathrm{AO}(\mathrm{t}-1)$ & $\mathrm{t}$ & $629.5^{*}$ & 628.9 & 629.4 & 628.4 & 629.5 & 633.7 \\
\hline Mashhad & $\mathrm{t}$ & $\operatorname{ENSO}(t)$ & $\mathrm{NCP}(\mathrm{t}-2)$ & $\mathrm{AO}(\mathrm{t}-8)$ & $\mathrm{NAO}(\mathrm{t}-9)$ & 652.4 & 645.3 & 642.3 & 641.9 & 638.0* & 664.7 \\
\hline Oroomieh & $\operatorname{ENSO}(\mathrm{t}-5)$ & $\mathrm{t}$ & $\mathrm{NCP}(\mathrm{t}-1)$ & NAO(t-9) & $\mathrm{AO}(\mathrm{t}-10)$ & 650.3 & 647.3 & 647.2 & 647.0 & $644.5^{*}$ & 654.3 \\
\hline Ramsar & $\mathrm{NCP}(\mathrm{t})$ & $\mathrm{ENSO}(\mathrm{t})$ & $\mathrm{NAO}(\mathrm{t}-6)$ & $\mathrm{t}$ & $\mathrm{AO}(\mathrm{t}-8)$ & 736.2 & $733.5^{*}$ & 732.5 & 733.0 & 733.3 & 742.6 \\
\hline Rasht & $\mathrm{NCP}(\mathrm{t}-1)$ & $\mathrm{ENSO}(\mathrm{t})$ & $\mathrm{NAO}(\mathrm{t})$ & $\mathrm{AO}(\mathrm{t}-1)$ & $\mathrm{t}$ & 712.8 & $710.2^{*}$ & 709.9 & 709.0 & 710.9 & 724.6 \\
\hline Sabzevar & $\mathrm{NCP}(\mathrm{t}-2)$ & $\operatorname{ENSO}(t)$ & $\mathrm{NAO}(\mathrm{t}-5)$ & $\mathrm{AO}(\mathrm{t}-8)$ & $\mathrm{t}$ & 643.4 & 639.0 & $635.1^{*}$ & 633.7 & 635.3 & 650.6 \\
\hline Saghez & $\operatorname{ENSO}(\mathrm{t}-1)$ & $\mathrm{NCP}(\mathrm{t}-2)$ & $\mathrm{AO}(\mathrm{t}-7)$ & $\mathrm{NAO}(\mathrm{t})$ & $\mathrm{t}$ & $671.2^{*}$ & 671.2 & 670.3 & 671.5 & 673.2 & 683.8 \\
\hline Sanandaj & $\mathrm{ENSO}(\mathrm{t})$ & $\mathrm{t}$ & $\mathrm{NAO}(\mathrm{t}-7)$ & $\mathrm{NCP}(\mathrm{t}-3)$ & $\mathrm{AO}(\mathrm{t}-1)$ & 653.5 & 651.2 & $647.0 *$ & 647.1 & 648.5 & 663.4 \\
\hline Shahrekord & $\mathrm{t}$ & $\mathrm{ENSO}(\mathrm{t})$ & $\mathrm{NCP}(\mathrm{t}-3)$ & $\mathrm{NAO}(\mathrm{t}-6)$ & $\mathrm{AO}(\mathrm{t}-7)$ & 642.3 & 632.7 & 627.4 & $627.1^{*}$ & 625.2 & 657.1 \\
\hline Shahroud & $\operatorname{ENSO}(t)$ & $\mathrm{NCP}(\mathrm{t}-3)$ & $\mathrm{AO}(\mathrm{t}-12)$ & $\mathrm{NAO}(\mathrm{t}-10)$ & $\mathrm{t}$ & 611.7 & $608.6^{*}$ & 606.7 & 607.8 & 609.3 & 617.3 \\
\hline Shiraz & $\mathrm{t}$ & $\operatorname{ENSO}(t)$ & $\mathrm{AO}(\mathrm{t}-8)$ & $\mathrm{NAO}(\mathrm{t}-6)$ & $\mathrm{NCP}(\mathrm{t}-1)$ & 673.2 & 668.5 & $667.0^{*}$ & 666.4 & 667.8 & 678.0 \\
\hline Tabriz & $\mathrm{t}$ & $\mathrm{NCP}(\mathrm{t}-1)$ & $\mathrm{NAO}(\mathrm{t}-7)$ & $\operatorname{ENSO}(\mathrm{t}-1)$ & $\mathrm{AO}(\mathrm{t}-5)$ & 615.2 & 609.5 & 602.4 & 595.1* & 595.4 & 649.5 \\
\hline Tehran Mehrabad & $\mathrm{t}$ & $\mathrm{NCP}(\mathrm{t}-9)$ & $\mathrm{ENSO}(\mathrm{t}-5)$ & $\mathrm{NAO}(\mathrm{t}-1)$ & $\mathrm{AO}(\mathrm{t}-3)$ & 629.9 & 624.6 & 623.7 & 623.9 & $620.9 *$ & 636.5 \\
\hline Torbat Heydarieh & $\operatorname{ENSO}(t)$ & $\mathrm{AO}(\mathrm{t}-8)$ & $\mathrm{t}$ & $\mathrm{NCP}(\mathrm{t}-2)$ & $\mathrm{NAO}(\mathrm{t}-5)$ & 652.1 & $648.5^{*}$ & 646.9 & 647.3 & 648.4 & 657.1 \\
\hline Yazd & $\mathrm{NAO}(\mathrm{t}-3)$ & $\mathrm{NCP}(\mathrm{t})$ & $\mathrm{AO}(\mathrm{t}-8)$ & $\operatorname{ENSO}(\mathrm{t}-12)$ & $\mathrm{t}$ & $636.2 *$ & 636.3 & 637.7 & 639.2 & 640.7 & 636.8 \\
\hline Zabol & $\mathrm{NCP}(\mathrm{t}-2)$ & $\mathrm{t}$ & $\operatorname{ENSO}(t)$ & $\mathrm{AO}(\mathrm{t}-12)$ & $\mathrm{NAO}(\mathrm{t}-10)$ & 664.5 & 659.9 & $657.6^{*}$ & 658.0 & 657.1 & 672.3 \\
\hline Zahedan & $\mathrm{t}$ & $\mathrm{NCP}(\mathrm{t}-6)$ & $\mathrm{ENSO}(\mathrm{t}-8)$ & $\mathrm{NAO}(\mathrm{t}-5)$ & $\mathrm{AO}(\mathrm{t}-5)$ & 603.2 & $600.2^{*}$ & 600.1 & 601.1 & 600.1 & 632.4 \\
\hline Zanjan & $\mathrm{ENSO}(\mathrm{t}-5)$ & $\mathrm{NCP}(\mathrm{t}-2)$ & $\mathrm{t}$ & $\mathrm{NAO}(\mathrm{t}-7)$ & $\mathrm{AO}(\mathrm{t}-9)$ & $620.6^{*}$ & 619.5 & 619.2 & 620.5 & 621.0 & 624.7 \\
\hline
\end{tabular}


Table 5. The optimal non-stationary model fitted to the x-series of October-September for estimation

\begin{tabular}{|c|c|c|c|}
\hline \multirow{2}{*}{ Station } & \multicolumn{2}{|l|}{ Optimal Non-stationary Model } & \multirow{2}{*}{ MK Test } \\
\hline & Location Parameter $(\gamma(t))$ & AIC & \\
\hline Abadan & $2949.7-10.9 t$ & 720.0 & $-4.84 * *$ \\
\hline Ahwaz & $2306.5+368.6 N A O(t-3)-136.2 E N S O(t-8)$ & 731.4 & 0.92 \\
\hline Arak & $4554.9-52.8 \operatorname{ENSO}(t)-2.04 t+84.3 N C P(t-3)$ & 646.7 & $-1.92 *$ \\
\hline Bam & $3440.3-4.1 t-61.1 \operatorname{ENSO}(t)$ & 678.6 & $-3.21 * *$ \\
\hline Bandar Abbas & $2717.3+234.8 N A O(t-12)+308.6 N C P(t)+3.5 t$ & 697.5 & 1.59 \\
\hline Bandar Anzali & $5856.6-140.5 \operatorname{ENSO}(t)-253.5 N A O(t-11)$ & 753.5 & -0.94 \\
\hline Birjand & $4229.6-47.9 \operatorname{ENSO}(t-1)+64.6 A O(t-8)$ & 611.9 & 0.34 \\
\hline Bushehr & $3608.4-6.2 t+226.7 N C P(t-8)$ & 669.3 & $-3.61 * *$ \\
\hline Esfahan & $4182.4+71.4 N C P(t-9)$ & 606.5 & -1.08 \\
\hline Gazvin & $4408.3-71.8 E N S O(t-1)+3.1 t$ & 650.0 & $2.39 * *$ \\
\hline Gorgan & $\begin{array}{l}4641.1+167.4 N C P(t-8)-34.3 E N S O(t-11)-1.1 t-127.6 A O(t-6)+ \\
\text { 119.4NAO(t) }\end{array}$ & 645.6 & $-2.20 *$ \\
\hline Kerman & $4202.2+0.12 t$ & 664.4 & -0.5 \\
\hline Kermanshah & $4588.1-38.1 \operatorname{ENSO}(t)$ & 637.9 & $-4.33 * *$ \\
\hline Khorramabad & $4502.7-98.9 \operatorname{ENSO}(t)$ & 685.6 & -0.15 \\
\hline Khoy & $4496.7+115.7 N C P(t-1)$ & 629.5 & -0.17 \\
\hline Mashhad & $\begin{array}{l}4538.8-4.8 t-79.4 \operatorname{ENSO}(t)+71.3 N C P(t-2)+147.0 A O(t-8)- \\
130.7 N A O(t-9)\end{array}$ & 638.0 & $-3.18^{* *}$ \\
\hline Oroomieh & $\begin{array}{l}4702.6-62.7 \text { ENSO }(t-5)-2.7 t+48.5 N C P(t-1)-144.5 N A O(t-9)+ \\
115.5 A O(t-10)\end{array}$ & 644.5 & $-2.31^{*}$ \\
\hline Ramsar & $5341.2+335.0 N C P(t)-109.6 \operatorname{ENSO}(t)$ & 733.5 & -1.43 \\
\hline Rasht & $5461.3+404.8 N C P(t-1)-95.9 \operatorname{ENSO}(t)$ & 710.2 & -0.65 \\
\hline Sabzevar & $4103.9+181.6 N C P(t-2)-63.9 \operatorname{ENSO}(t)-89.2 N A O(t-5)$ & 635.1 & 0.32 \\
\hline Saghez & $4756.8-113.6 \operatorname{ENSO}(t-1)$ & 671.2 & -1.52 \\
\hline Sanandaj & $4656.8-101.6 \operatorname{ENSO}(t)-2.5 t-100.0 N A O(t-7)$ & 647.0 & -1.62 \\
\hline Shahrekord & $4451.3+4.9 t-74.4 \operatorname{ENSO}(t)+147.0 N C P(t-3)-50.9 N A O(t-6)$ & 627.1 & $3.75^{* *}$ \\
\hline Shahroud & $4304.8-42.2 \operatorname{ENSO}(t)+77.5 N C P(t-3)$ & 608.6 & -0.48 \\
\hline Shiraz & $4400.0-4.0 t-59.1 \operatorname{ENSO}(t)+83.1 A O(t-8)$ & 667.0 & $-2.31^{*}$ \\
\hline Tabriz & $4634.4-4.8 t+117.0 N C P(t-1)-99.5 N A O(t-7)-41.2 \operatorname{ENSO}(t-1)$ & 595.1 & $-5.33 * *$ \\
\hline Tehran Mehrabad & $\begin{array}{l}4244.7-2.1 t+93.4 N C P(t-9)-7.7 \operatorname{ENSO}(t-5)+116.1 N A O(t-1)- \\
101.7 A O(t-3)\end{array}$ & 620.9 & $-2.6 * *$ \\
\hline Torbat Heydarieh & $4477.1-58.5 \operatorname{ENSO}(t)+88.9 A O(t-8)$ & 648.5 & $1.95^{*}$ \\
\hline Yazd & $3755.4+59.3 N A O(t-3)$ & 636.2 & -0.81 \\
\hline Zabol & $3548.3+258.6 N C P(t-2)-3.6 t-66.2 E N S O(t)$ & 657.6 & $-1.71^{*}$ \\
\hline Zahedan & $4145.4-4.0 t+65.8 N C P(t-6)$ & 600.2 & $-4.98 * *$ \\
\hline Zanjan & $4602.9-34.6 \operatorname{ENSO}(t-5)$ & 620.6 & 1.19 \\
\hline
\end{tabular}

${ }^{*}$ indicates the $5 \%$ significance level, and ${ }^{* *}$ indicates the $1 \%$ significance level. 


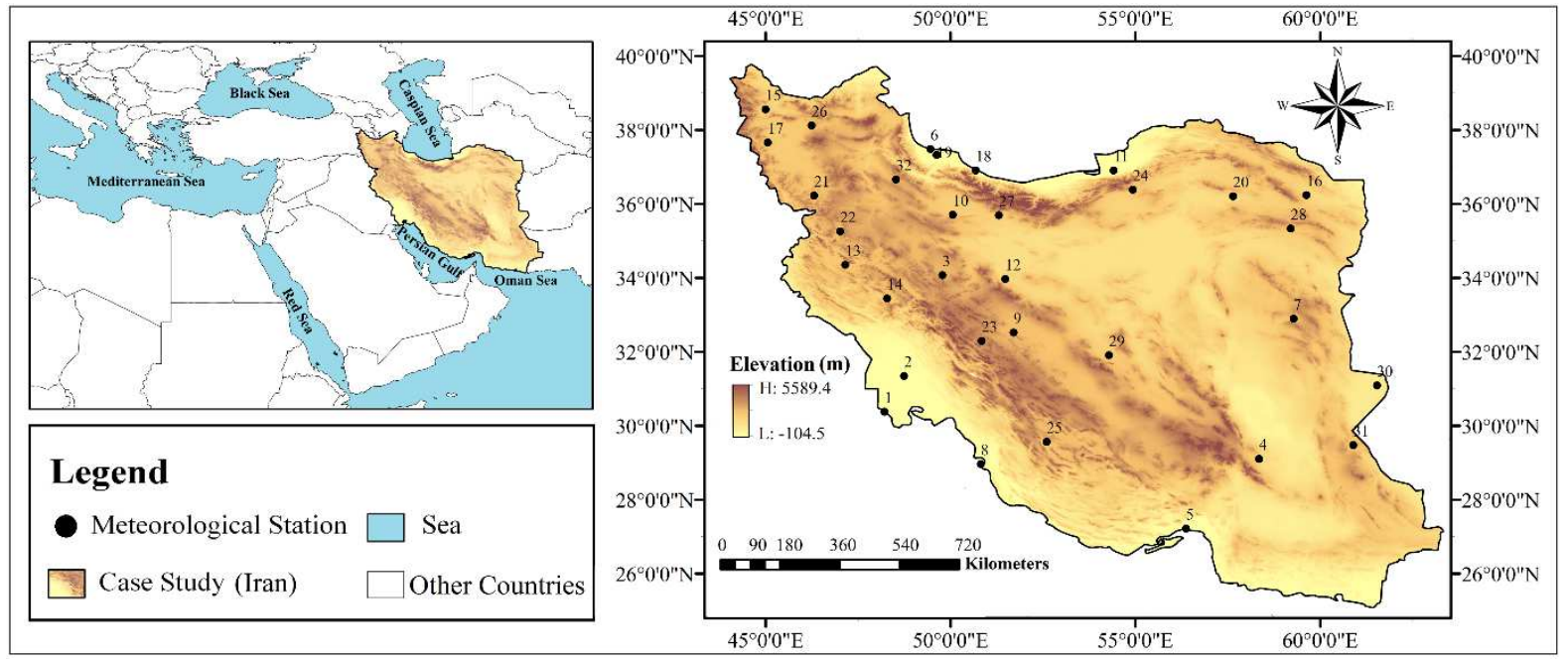

Fig. 1. Positions of the chosen weather stations in the study area, Iran. The stations numbers have been described in Table 1. 


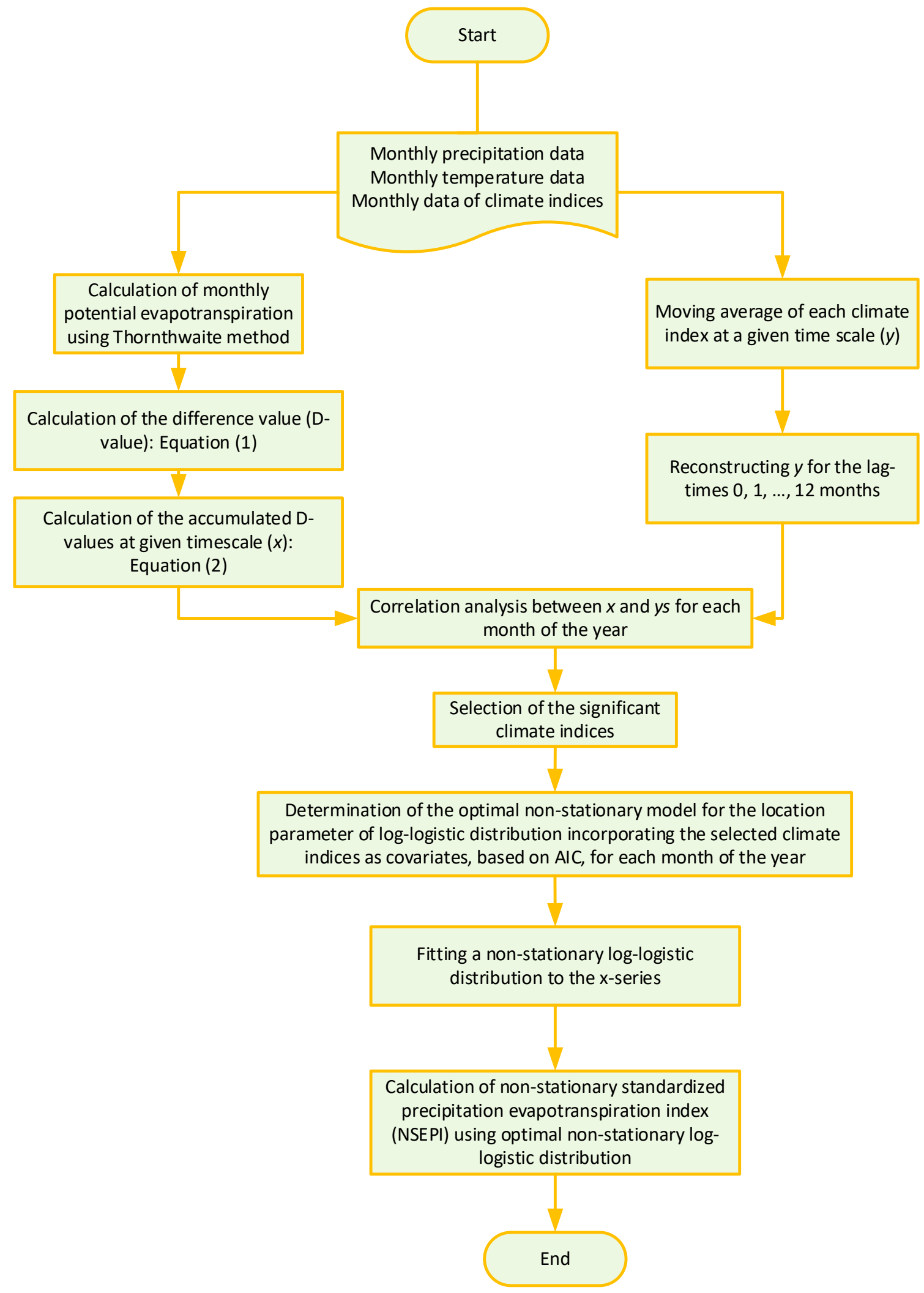

Fig. 2. Displaying the steps for calculation of NSPEI in this study 

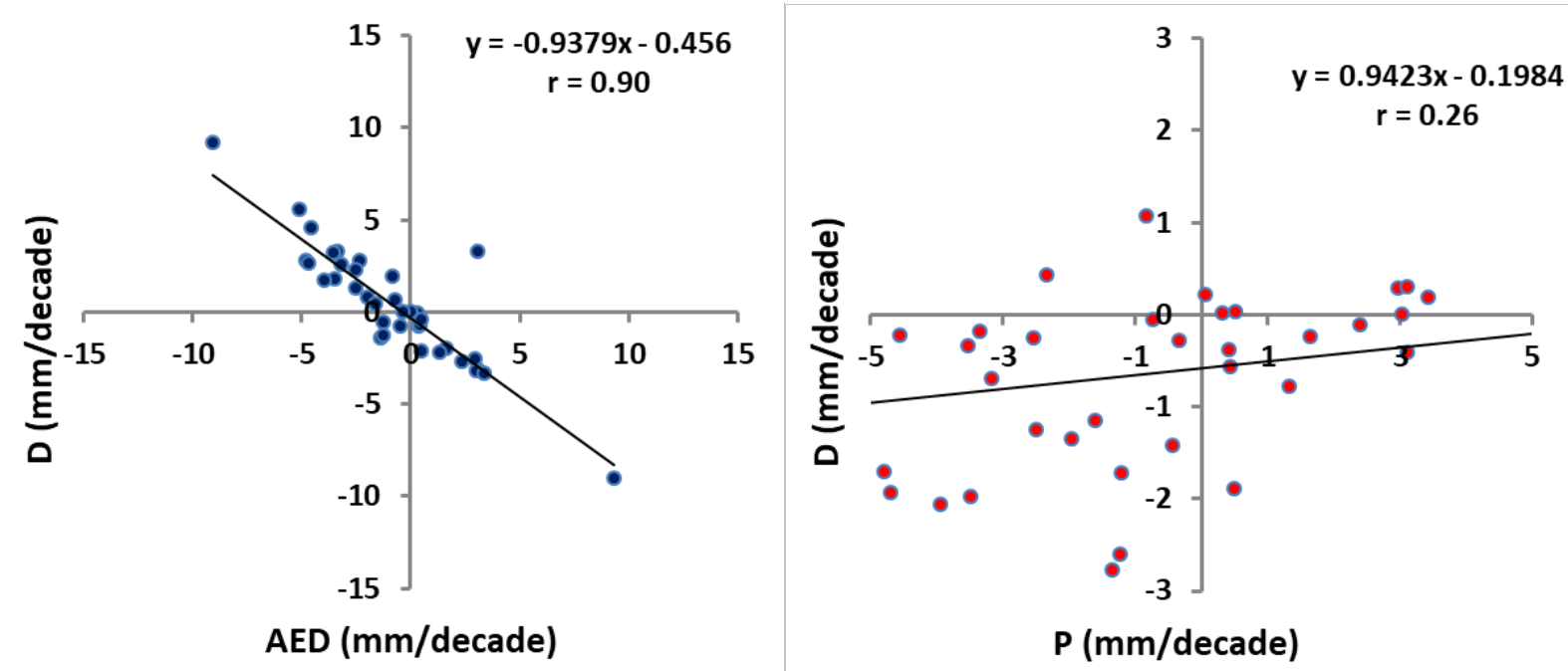

Fig. 3. The trend magnitudes in D vs. the trend magnitudes in AED (left panel) and the trend

magnitudes in D vs. the trend magnitudes in $\mathrm{P}$ (right panel) across all chosen stations.

928 


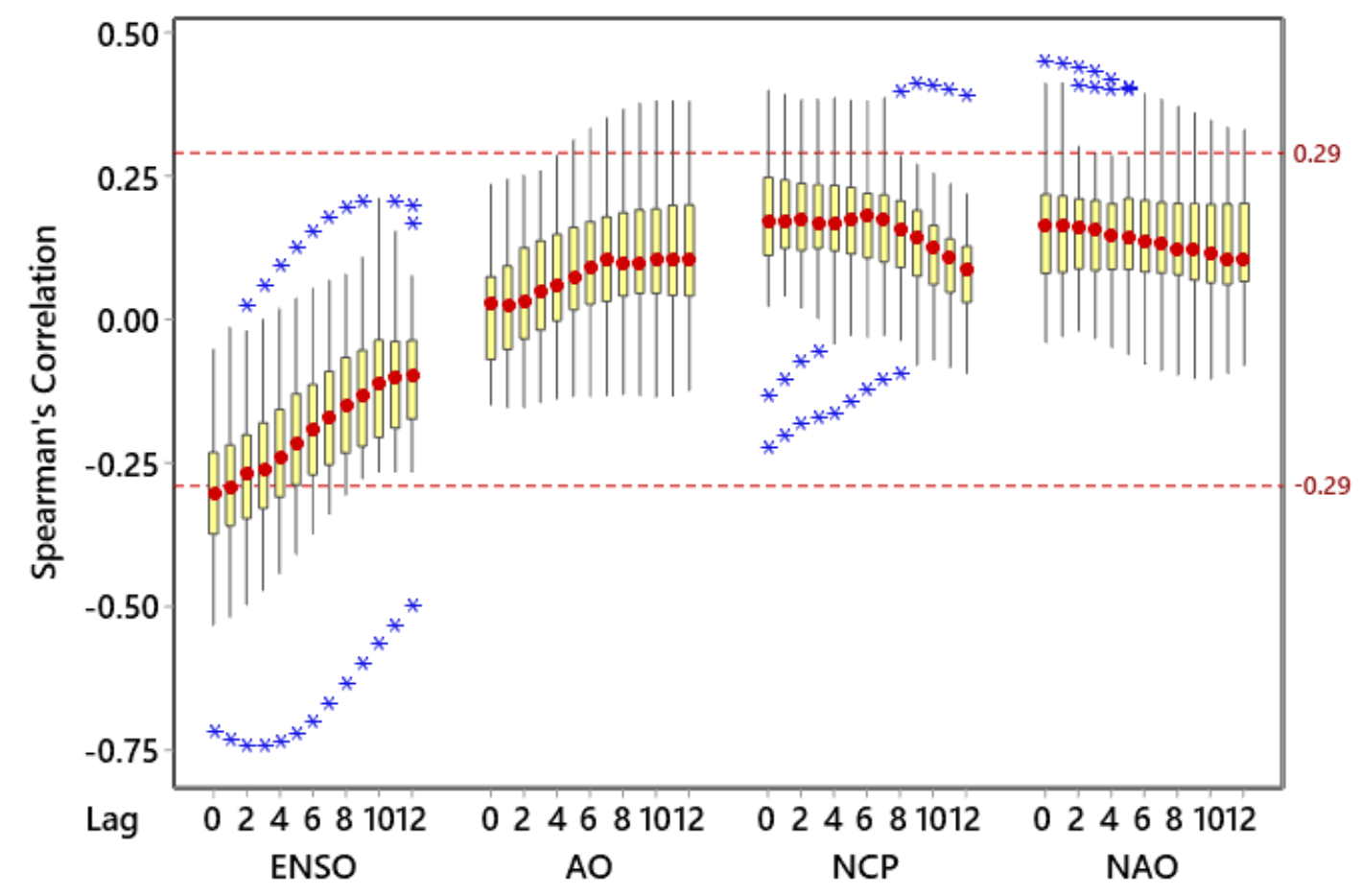

Fig. 4. Boxplot of the Spearman's correlation coefficients between D and each of the four 948 selected climate indices (ENSO, AO, NCP, and NAO) in this study for the lag-times 0-12 949 months. Each box-whisker represents the $5^{\text {th }}, 25^{\text {th }}, 50^{\text {th }}, 75^{\text {th }}$, and 95 th percentiles across the 950 stations and the outliers are indicated with the stars. The red dotted lines show the $95^{\text {th }}$ 951 confidence interval of correlation coefficients. 


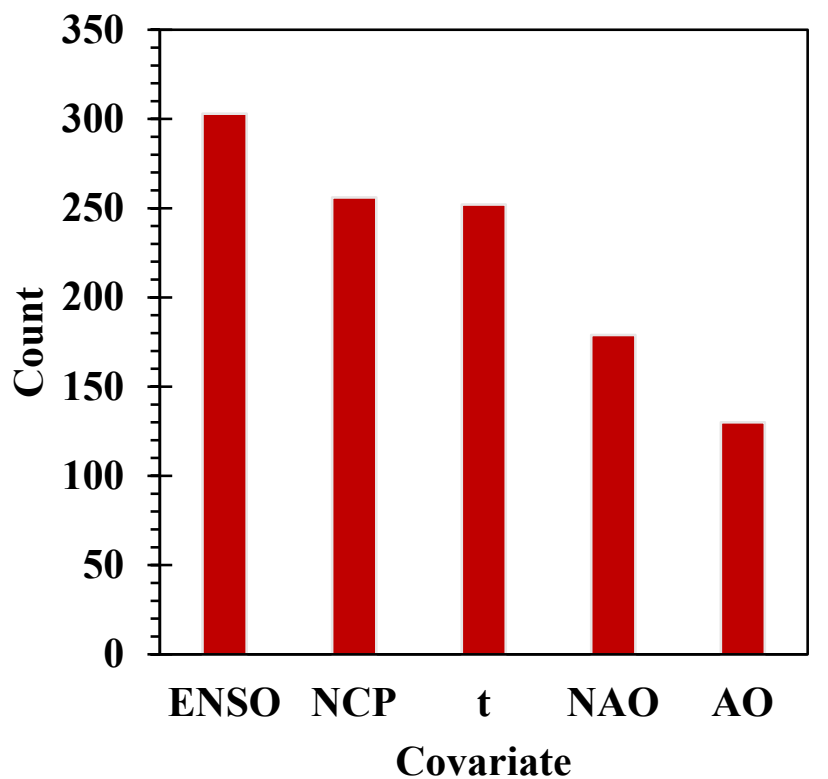

Fig. 5. Comparison of the five covariates in terms of the times used in the non-stationary 
a) Yazd (Arid)

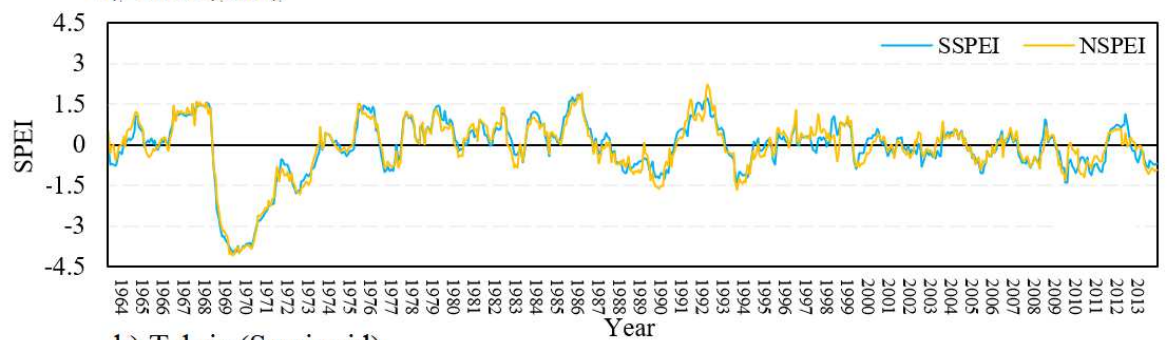

b) Tabriz (Semi-arid)

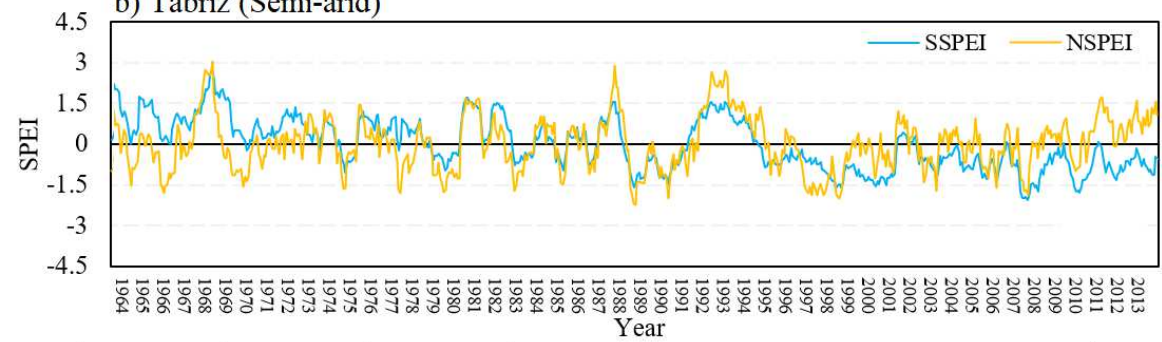

c) Gorgan (Mediterranean)
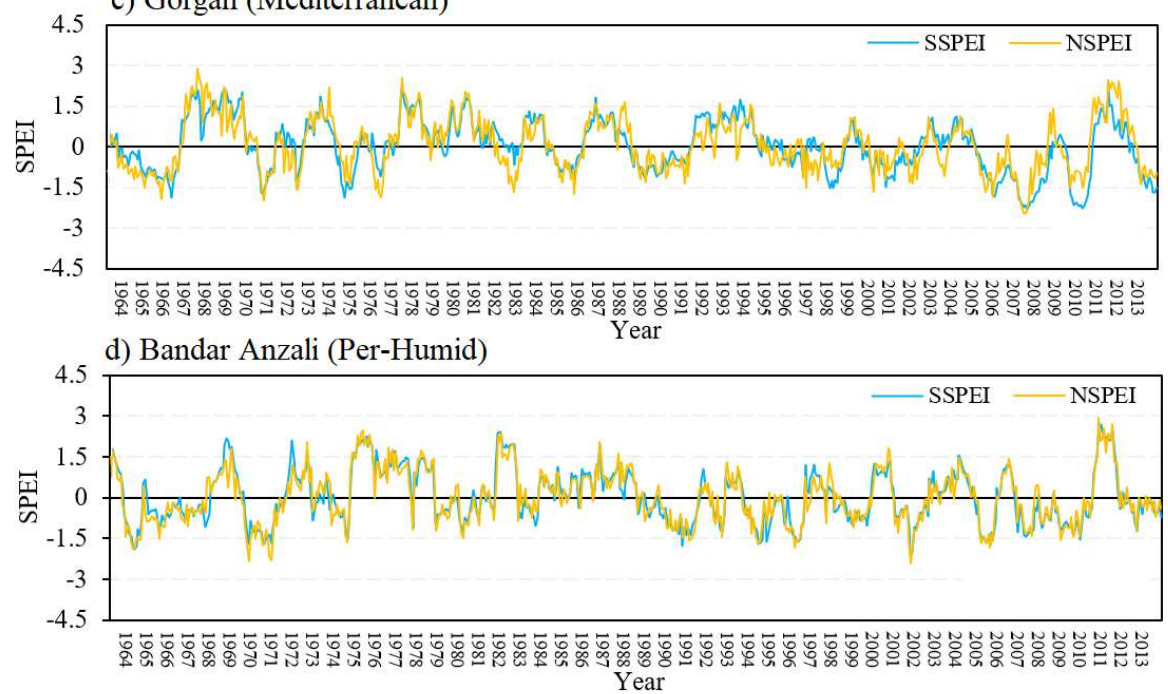
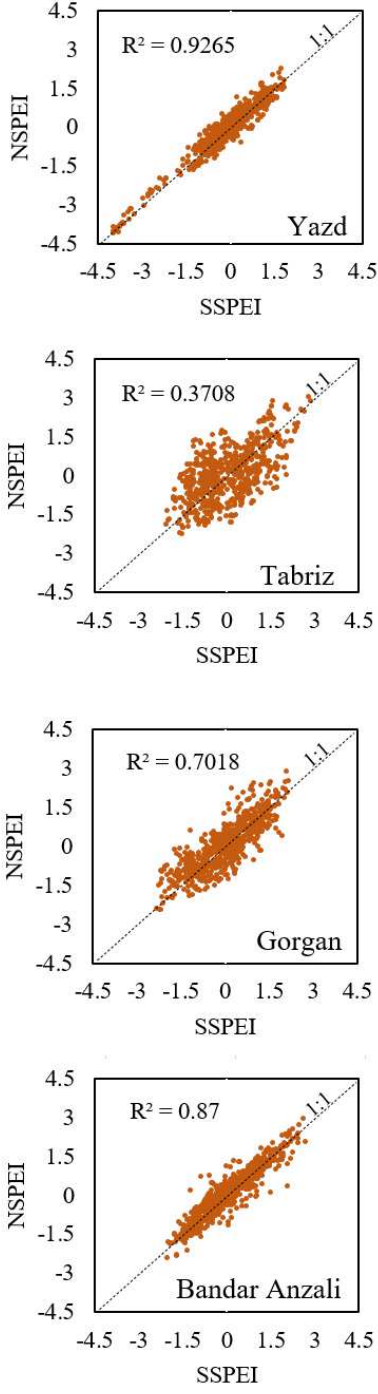

976

Fig. 6. Comparison of the SSPEI and NSPEI time series at the sample stations: a) Yazd, b) 977

Tabriz, c) Gorgan, and d) Bandar Anzali. The right-side diagrams display the scatter plots of 978

NSPEI vs. SSPEI at the same stations. 

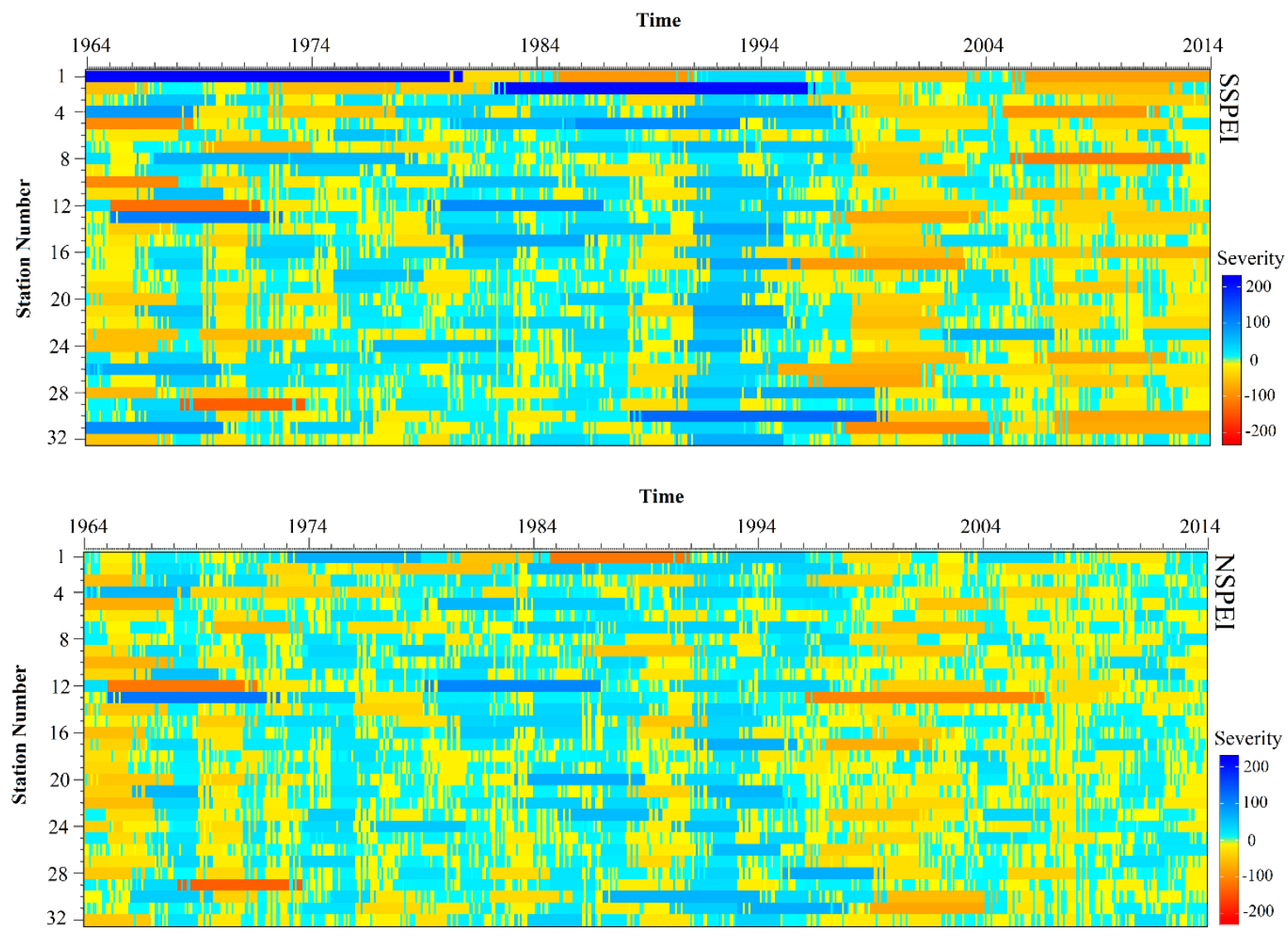

Fig. 7. Temporal variations of the drought/wet events durations and severities for the whole 

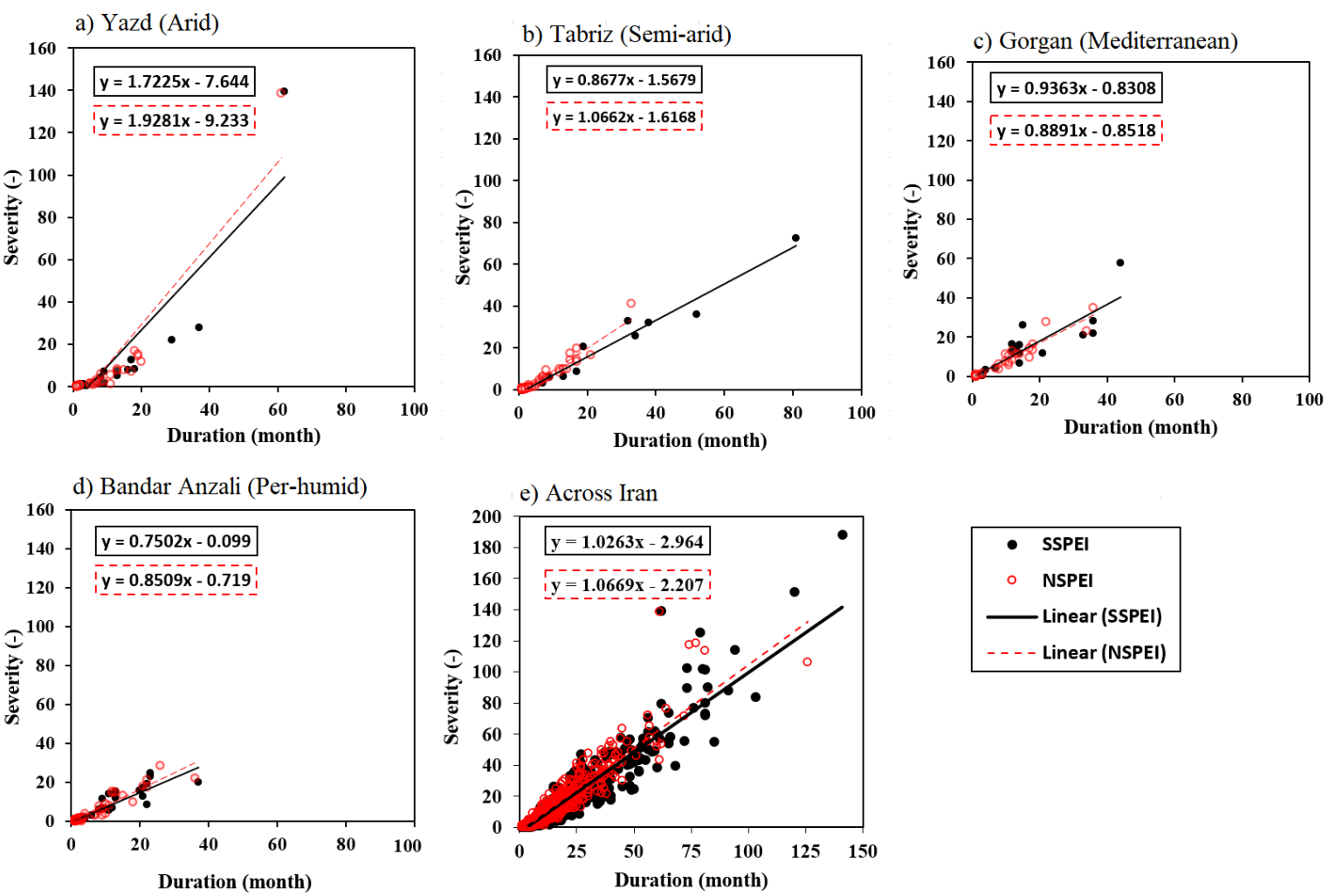

Fig. 8. The severity-duration relationships for SSPEI and NSPEI at the sample stations (a)

Yazd, b) Tabriz, c) Gorgan, and d) Bandar Anzali), and across Iran (e). 


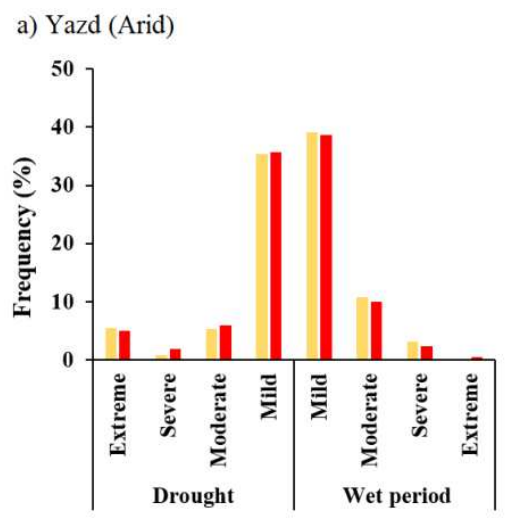

b) Tabriz (Semi-arid)
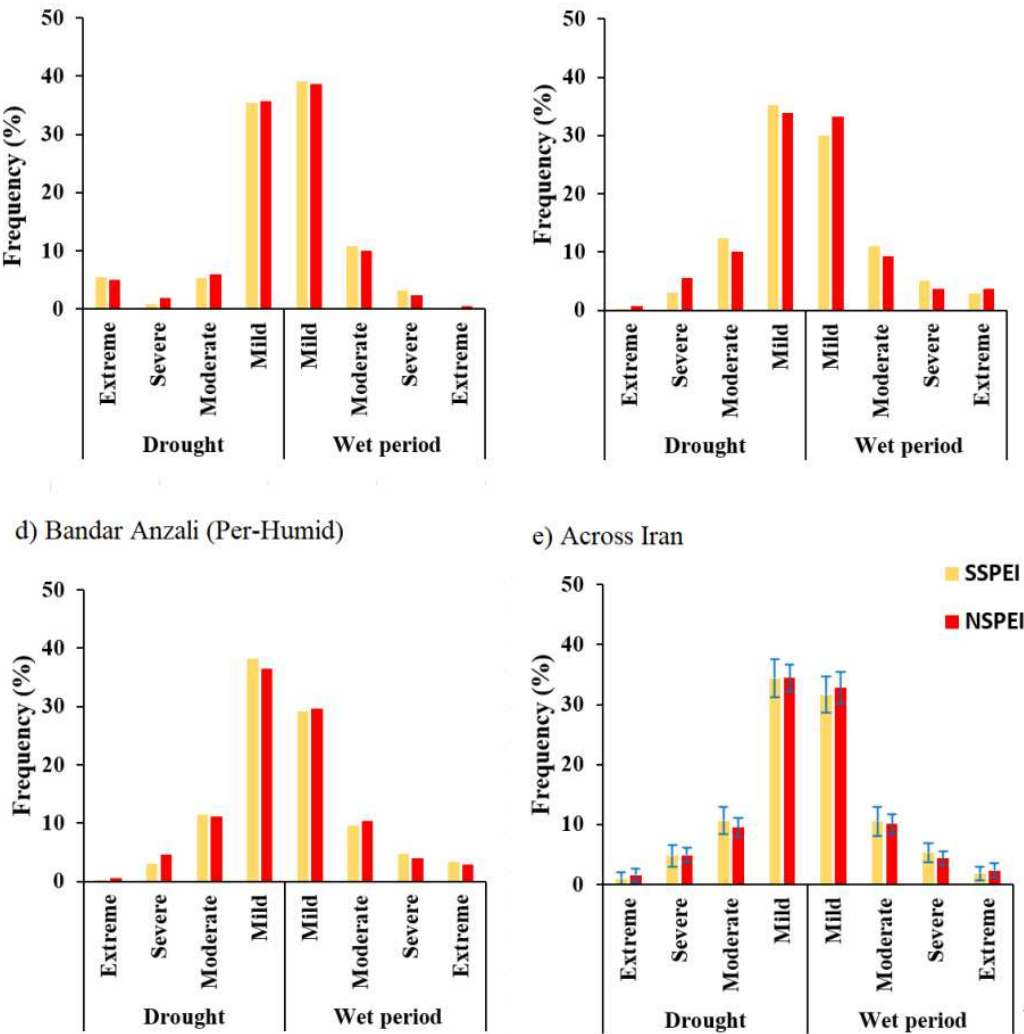

e) Across Iran

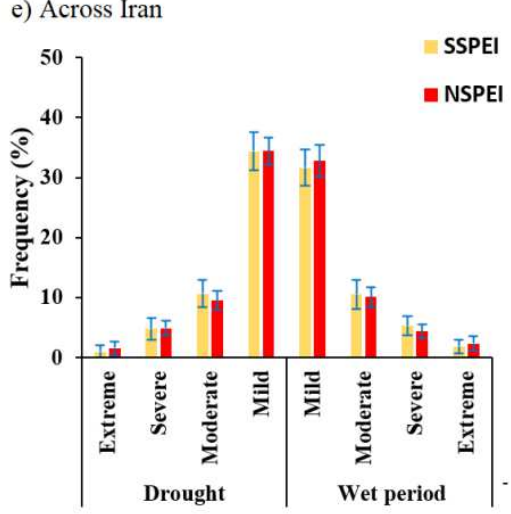

c) Gorgan (Mediterranean)

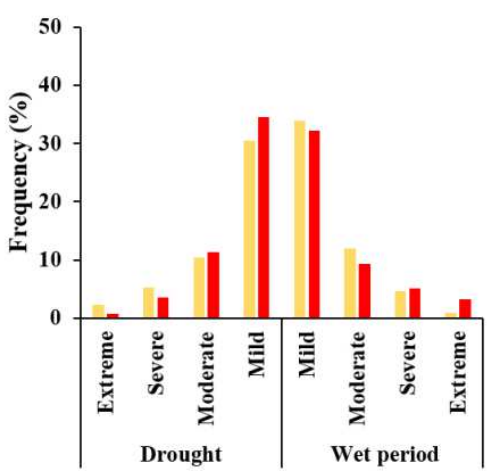

Fig. 9. Frequency of drought and wet period classes for SSPEI and NSPEI at the sample 

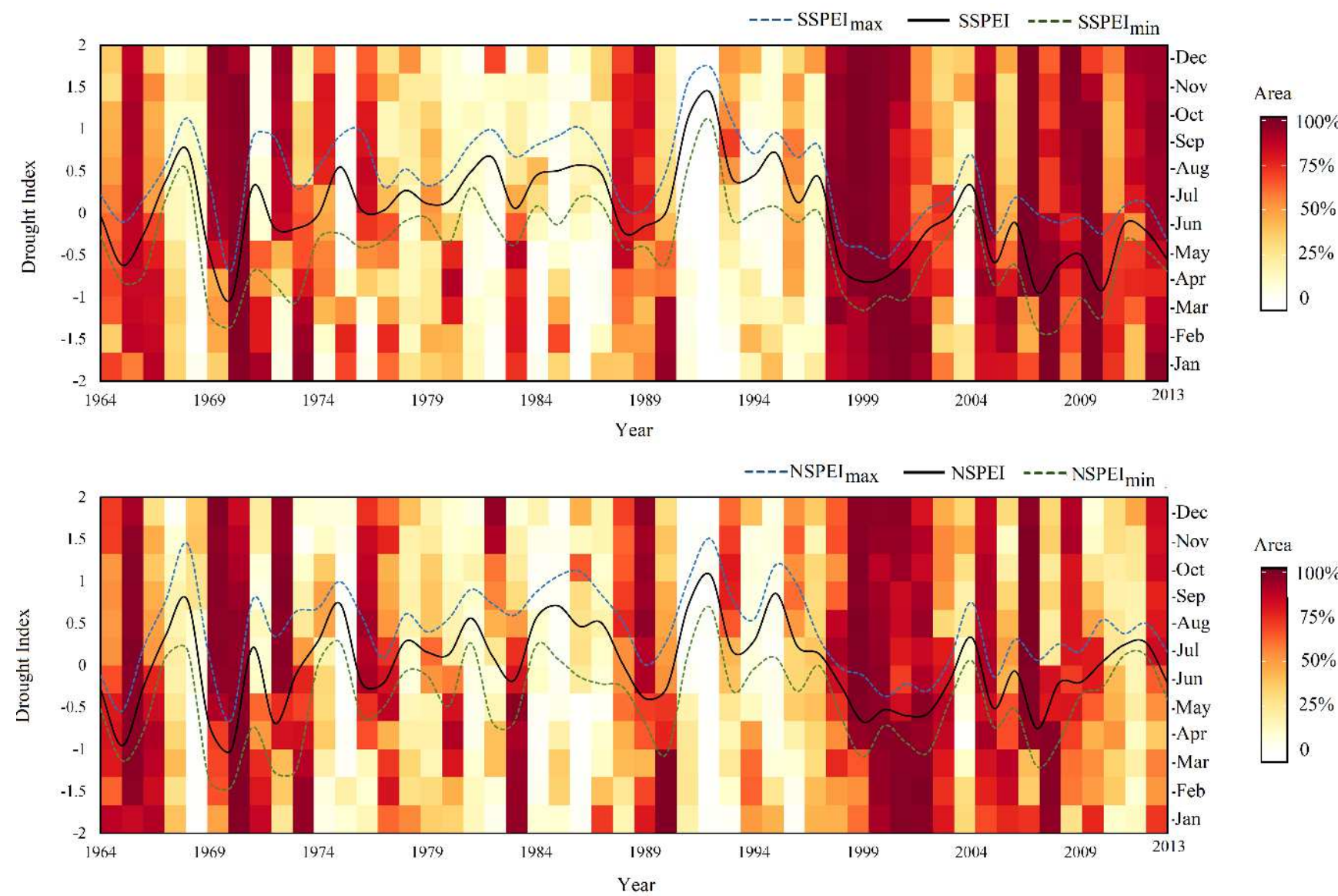

Area

Fig. 10. The water-year (i.e. October-September) average, minimum, and maximum time series of

SSEPI (upper) and NSPEI (lower) across the studied stations, accompanying the percentage areas of 

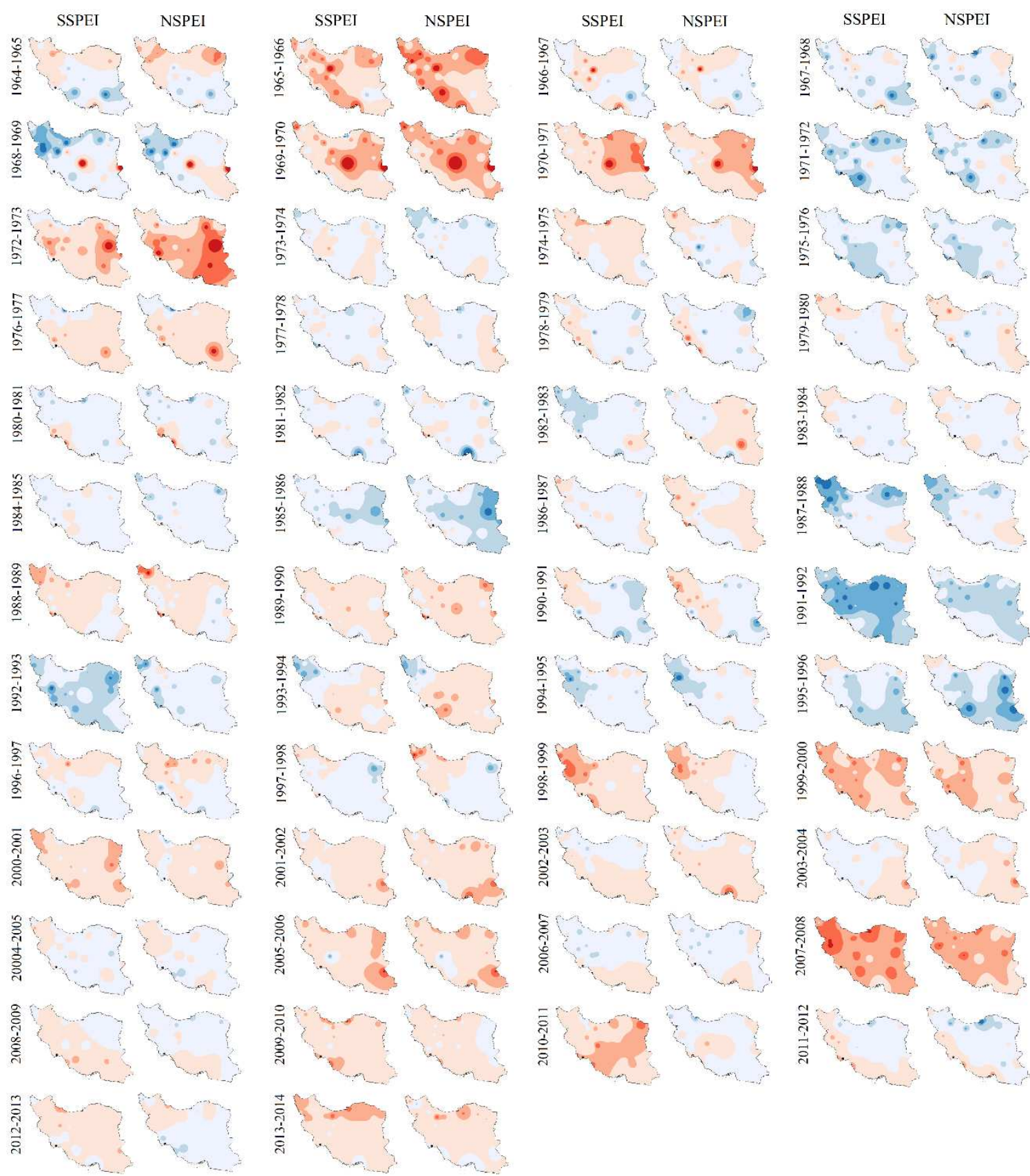

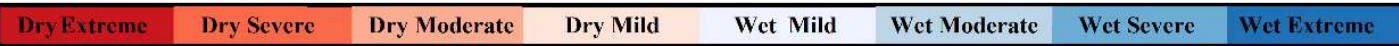

Fig. 11. Spatiotemporal variations of the drought and wet period classes for SSPEI and 


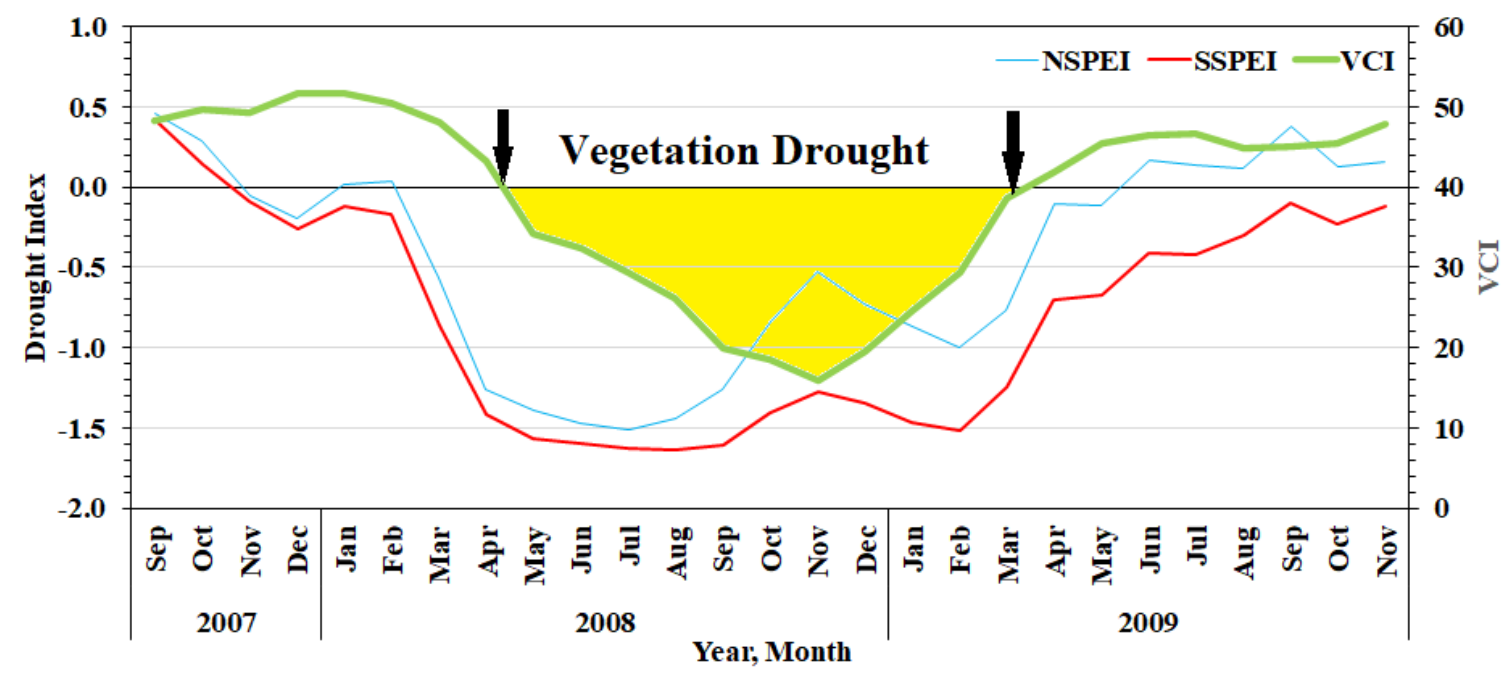

Fig. 12. The average series of SSPEI, NSPEI, and VCI across the studied stations during the 